\title{
Solutions for submucosal injection in endoscopic resection: a systematic review and meta-analysis
}

Authors

Institutions
Alexandre Oliveira Ferreira ${ }^{1,}{ }^{*}$, Joana Moleiro ${ }^{2,}$ *, Joana Torres ${ }^{1}$, Mario Dinis-Ribeiro ${ }^{3,4}$

Institutions are listed at the end of article. submitted:

6. December 2014 accepted after revision: 11. August 2015

\section{Bibliography}

Dol http://dx.doi.org/

10.1055/s-0034-1393079

Endoscopy International Open

2016; 04: E1-E16

(c) Georg Thieme Verlag KG

Stuttgart · New York

E-ISSN 2196-9736

\section{Corresponding author}

Alexandre Oliveira

\section{Ferreira, MD}

Hospital Beatriz Ângelo

Department of

Gastroenterology

Avenida Carlos Teixeira 3

2674-514 Loures

Portugal

Fax: +351-21-9847209

alex.gastrohep@gmail.com
Published online: 6.10.2015

Background and aims: Submucosal injection is standard practice in endoscopic mucosal resection of gastrointestinal lesions. Several solutions are used. Our aim was to systematically review their efficacy and safety.

Patients and methods: We performed a systematic review and meta-analysis using a random effects model of randomized controlled trials (RCTs) from MEDLINE. Studies in animal models were qualitatively assessed for efficacy and safety. Results: In total, 54 studies were qualitatively assessed. Eleven RCTs were analyzed, two of which were on endoscopic submucosal dissection (ESD). The quantitative synthesis included nine RCTs on endoscopic mucosal resection (EMR), comprising 792 subjects and 793 lesions. Mean lesion size was $20.9 \mathrm{~mm}$ (range $8.5-46 \mathrm{~mm}$ ). A total of 209 lesions were randomized to sodium hyaluronate (SH) vs normal saline (NS), 72 to $50 \%$ dextrose

\section{Introduction}

$\nabla$

Gastrointestinal tract cancer represents the leading cause of cancer death worldwide, with an estimated mortality over 1.75 million [1]. Early endoscopic detection and treatment of potentially curable cancers or precancerous lesions could potentially lead to a reduction of gastrointestinal cancer incidence and cancer related mortality [2-5]. In the past decades, endoscopic resection therapies have gradually improved and gained more importance for premalignant lesions and noninvasive early cancers with a low risk of lymph node metastasis. The survival after endoscopic removal of an early cancer may be similar to that after surgical resection, providing the rationale for this approach $[6,7]$.

Resection-based modalities consist of endoscopic mucosal resection (EMR) and endoscopic submu-
(D50) vs NS, 82 to D50 vs SH, 43 to succinylated gelatin, 25 to hydroxyethyl starch and 36 to fibrinogen. In total, 385 were randomized to NS as controls. NS and SH are the best studied solutions and seem to be equally effective in achieving complete resection (OR 1.09; 95\%CI 0.82, 1.45). No solution was proven to be superior in complete resection rate, post-polypectomy bleeding or coagulation syndrome/perforation incidence. Many solutions have been tested in animal studies and most seem more effective for mucosal elevation than NS.

Conclusions: There are several solutions in clinical use and many more under research, but most are poorly studied. SH seems to be clinically equivalent to NS. There are no significant differences in post-polypectomy complications. Larger RCTs are needed to determine any small differences that may exist between solutions.

cosal dissection (ESD). Injection-assisted EMR was first introduced in 1955 for rigid sigmoidoscopy [8] and then in 1973 for flexible colonoscopy [9]. In the following years, improvements in the EMR techniques, such as cap-assisted EMR and ligation method, have been introduced $[10,11]$, and nowadays, EMR is a widely used and useful method to resect minimally invasive benign and early malignant lesions of the gastrointestinal tract [12]. However, despite its efficacy, this method is sometimes associated with local recurrence, especially when lesions larger than $40 \mathrm{~mm}$ are resected in a piecemeal fashion [13]. To overcome this limitation, ESD has been developed, allowing en bloc resection of superficial neoplasms and providing better histopathological diagnosis and decreased local recurrence rates [14-16].

Endoscopic resection techniques are aided by mucosal elevation through the injection of a solution into the submucosal space. This technique may reduce complications, such as perforation or 
bleeding and improve the technical feasibility of the procedure. The volume of injected fluid is highly variable and depends on the size and location of the lesion, and repeated injections may be needed for complete removal.

Several solutions have been used to lift the mucosal lesion, but the optimal solution is still a matter of debate. It is accepted that the "ideal" solution for submucosal injection should provide a thick submucosal fluid cushion, remain in the submucosal space long enough to safely allow EMR or ESD, and preserve tissue specimens and allow for precise pathologic staging.

In this setting, normal saline (NS) has been the most widely used solution as it is simple to use and available at a low cost. However, the mucosal protrusion created by the submucosal injection of normal saline solution is only maintained for a short period of time. This may not have a significant impact on the removal of small lesions but, when performing longer procedures or resecting larger lesions, the need for repeated injections in order to maintain the cushion may become problematic and the risk of perforation may be higher. In order to overcome these limitations and to improve the technical feasibility of EMR and ESD, several solutions have been studied. Submucosal injection of glucose solution, glycerol, sodium hyaluronate (SH), colloids, hydroxypropyl methylcellulose, fibrinogen solution, autologous blood, and other alternatives have been investigated in different contexts. Nevertheless, these solutions are also associated with some caveats: they can be difficult to prepare or administer, available at a high cost or not readily available, or may be associated with toxicity.

In the past few years, several substances with different properties have been studied in ex vivo and in vivo studies. Among these, only a few have been evaluated in clinical trials. At the present time, no definitive proof of the superiority of any solution has been provided and there is no systematic review or meta-analysis on this topic.

\section{Objectives}

$\nabla$

The primary objective of this review was to identify and evaluate the safety and effectiveness of the available solutions for submucosal injection in endoscopic mucosal resection techniques (polypectomy, mucosal resection, and submucosal dissection) in human patients. As secondary objectives, we aimed to evaluate the duration of the effect, and the local deleterious effects of the solutions on the submucosal tissue, including those studies performed on animals.

\section{Material and methods \\ $\nabla$}

We performed a systematic review and a meta-analysis to evaluate the effectiveness and safety of existing solutions for submucosal injection in endoscopic mucosal resection or dissection. This review was registered on the International prospective register of systematic reviews, PROSPERO: CRD42014009577.

We considered all published randomized controlled trials for the quantitative synthesis. We performed a separate analysis for ESD and EMR. For the overall qualitative synthesis, we included nonrandomized trials, and observational studies (cohort, case-control, case series and case reports) evaluating the safety and effectiveness of submucosal injection solutions, regardless of blinding and language.
For the primary outcome, we included studies with humans submitted to upper or lower gastrointestinal endoscopy. For the secondary outcomes, we also included animal studies (including ex vivo).

We included procedures where polypectomy, EMR or ESD were performed after the injection of submucosal solutions had taken place, either in the esophagus, stomach, colon or rectum.

\section{Primary outcome}

Complete resection of the lesion-histological determination of en bloc lesion free margins or endoscopic determination of no residual lesion. Endoscopic determination included the lack of residual lesion as reported by the endoscopist (with or without chromoendoscopy) or the inclusion of resection marks in the resected specimen or negative follow-up with tissue forceps biopsies from the resection site.

\section{Secondary outcomes}

Number of injections given; volume injected; duration of submucosal cushion; procedure time; endoscopic complications; residual lesion at follow-up; tissue injury.

\section{Search strategy}

We individually searched MEDLINE and included all studies published until March 2014. The electronic search was performed using the following key words: submucosal injection AND (endoscopic AND resection OR EMR OR ER OR mucosectomy OR endoscopic submucosal dissection OR ESD OR polypectom*) AND (solution* OR saline OR hyaluron* OR glycerol OR hypertonic OR fibrinogen OR epinephrine OR adrenaline OR dextrose OR blood OR gelatin OR jelly OR mannitol OR sodium alginate OR carboxymethylcellulose OR albumin OR succiny* OR indigo OR methylene) AND (complete resection OR RO OR adverse event* OR complication* OR injection* OR volume OR duration).

\section{Study selection}

Two authors (AF, JM) independently scanned all titles and abstracts for relevance by electronic search. A third author (JT) intervened in case of disagreement.

\section{Data extraction}

Data extraction was performed independently by two authors (AF, JM) using a data extraction form to evaluate risk of bias according to the Cochrane Handbook for Systematic Reviews of Interventions. Studies were classified as high risk, low risk or unclear risk of bias.

The end points were rate of complete resection (primary end point), number of submucosal injections, total volume $(\mathrm{mL})$ used, duration of submucosal cushion (min), procedural time ( $\mathrm{min}$ ), rate of en bloc resection, incidence of endoscopic complications (perforation and bleeding), recurrence rate at follow-up and incidence of tissue injury or fibrosis.

\section{Data synthesis}

We provide a description of the findings including a summary of the study's results by intervention.

We performed the analysis in STATA 13 (Stata Corp., Texas, United States) and the flow diagram using Review Manager 5.We meta-analyzed the complete resection rate and the incidence of adverse events (bleeding and perforation), using both randomeffects and fixed-effect meta-analyses but we only report the random-effects meta-analyses, since the two methods concur- 


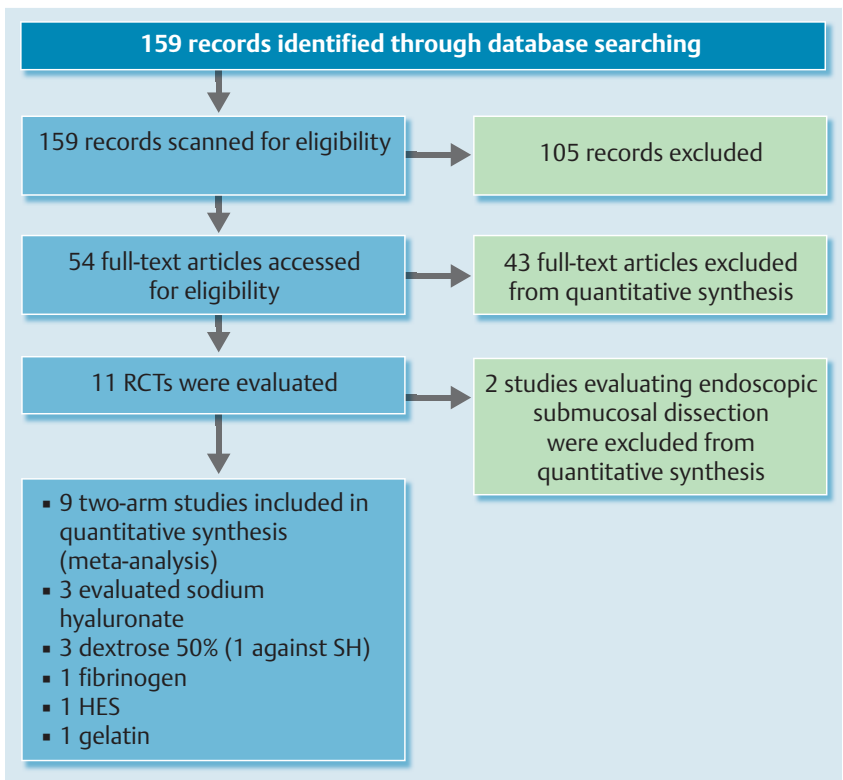

Fig. 1 Flow diagram with the selected studies for the meta-analysis.

red. We present odds ratios with a $95 \%$ confidence interval. Heterogeneity was assessed using the $I^{2}$ statistic. We produced a summary of findings table, rating the quality of evidence of the primary outcome.

\section{Results}

The electronic search resulted in a total of 159 published manuscripts that were scanned based on the title and abstract; 105 did not meet the inclusion criteria. The remaining 54 were assessed for eligibility using the full text articles and 11 were initially included for quantitative analysis. The flow diagram is shown in - Fig. 1, and the details of the studies are shown in $\bullet$ Table 1. Since there were only two studies on ESD and with different solutions (Mesna and SH) $[17,18]$, a meta-analysis was not performed. In these studies, 53 lesions were randomized to Mesna (vs NS) and 33 to SH (vs NS). There were 88 lesions randomized as controls. In the Mesna RCT [17], Sumiyama and colleagues aimed to evaluate the procedural time with Mesna compared to NS for gastric epithelial lesions. There was no statistically significant difference in this outcome. There were no differences in other outcomes such as R0 resection rate and adverse events (bleeding and perforation). Kim et al. [18] designed an RCT to compare SH to NS with "clinical usefulness" (a combination of en bloc resection and the need for additional injection) as the primary outcome. They randomized 76 gastric lesions and demonstrated a significant effect of $\mathrm{SH}$ in increasing the usefulness rate (90.9\% vs $61.1 \%$; $P=0.004$ ).

The nine EMR studies were all two-arm RCTs; eight of them used NS as the control group and only one used SH as the control [19]. Three trials evaluated SH solutions [20-22], three trials evaluated D50 [19,23, 24], and the others evaluated fibrinogen [25], hydroxyethyl starch (HES) [26], and succinylated gelatin (SG) [27]. The three studies that were excluded from the meta-analysis did not report the outcome of interest [28-30].

Quality assessment of the nine RCT determined that six had a low risk of bias on the generation of the randomization sequence and allocation concealment; six had kept double blinding, while two studies failed to report adequate blinding of the subjects and personnel, and one reported no blinding.

In the EMR studies, a total of 792 subjects and 793 lesions were included for analysis. The majority were male patients (56.7\%) and their mean age was $63.6 \pm 3.9$ years. Mean lesion size was $20.9 \mathrm{~mm}$ (range $8.5-46 \mathrm{~mm}$ ).

After pooling, 209 lesions were randomized to SH (vs NS), 72 to D50 (vs NS), 82 to D50 (vs SH), 43 to SG, 25 to HES and 36 to fibrinogen. In total, 385 were randomized to NS as controls.

Six studies were performed on colorectal lesions, one on gastric, and two using both gastric and colorectal lesions.

\section{Meta-analysis results}

Complete resection rate

All the nine studies included in the meta-analysis reported the resection efficacy and explicitly provided the complete resection rate (either by endoscopic evaluation or histological confirmation). The analysis results are shown as a forest plot in $\bullet$ Fig. 2 ,

Table 1 Characteristics of the randomized controlled trials included in the meta-analysis.

\begin{tabular}{|c|c|c|c|c|c|c|c|c|}
\hline Study (reference) & Country & $\mathbf{n}$ & $\begin{array}{l}\text { Lesion size, } \\
\mathrm{mm}\end{array}$ & Intervention & Control & RO A, \% & RO B, \% & $P$ value \\
\hline \multicolumn{9}{|l|}{ Stomach (ESD) } \\
\hline Sumiyama et al. (2014) [17] & Japan & 100 & 18.29 & Mesna & NS & 100 & 98.8 & NS \\
\hline Kim et al. (2013) [18] & South Korea & 63 & 13.84 & $\mathrm{SH}$ & NS & $90.9^{*}$ & $61.1^{*}$ & 0.004 \\
\hline \multicolumn{9}{|l|}{ Stomach (EMR) } \\
\hline Yamamoto et al. (2008) [22] & Japan & 140 & $5-20$ & $\mathrm{SH}$ & NS & 92.8 & 94.3 & 0.745 \\
\hline \multicolumn{9}{|l|}{ Stomach and colon (EMR) } \\
\hline Varadarajulu et al. (2006) [24] & USA & 60 & 22.5 & D50 & NS & 96.3 & 80.0 & 0.09 \\
\hline Lee et al. (2006) [25] & South Korea & 72 & 17.98 & Fibrinogen & NS & 86.1 & 80.6 & 0.53 \\
\hline \multicolumn{9}{|l|}{ Colorectal (EMR) } \\
\hline Kishihara et al. (2012) [21] & Japan & 94 & - & $\mathrm{SH}$ & NS & 97.8 & 93.8 & 0.06 \\
\hline Yoshida et al. (2012) [20] & Japan & 189 & 8.54 & $\mathrm{SH}$ & NS & 79.5 & 65.6 & 0.03 \\
\hline Fasoulas et al. (2012) [26] & Greece & 49 & 46 & HES & NS & 96.0 & 95.8 & 0.94 \\
\hline Moss et al. (2010) [27] & Australia & 80 & 37.5 & SG & NS & 90.0 & 90.0 & 1.0 \\
\hline Katsinelos et al. (2008) [23] & Greece & 92 & 23 & D50 & NS & 93.3 & 87.2 & 0.13 \\
\hline Hurlstone et al. (2008) [19] & UK & 163 & 19.1 & D50 & $\mathrm{SH}$ & 72.0 & 69.1 & $>0.01$ \\
\hline
\end{tabular}

RO A, complete resection rate in active group; R0 B, complete resection rate in control group; ESD, endoscopic submucosal dissection; EMR, endoscopic mucosal resection; SH, sodium hyaluronate; NS, normal saline; D50, 50\% dextrose; SG, succinylated gelatin.

* These proportions refer to clinical usefulness rate (complete resection within one additional submucosal injection). 


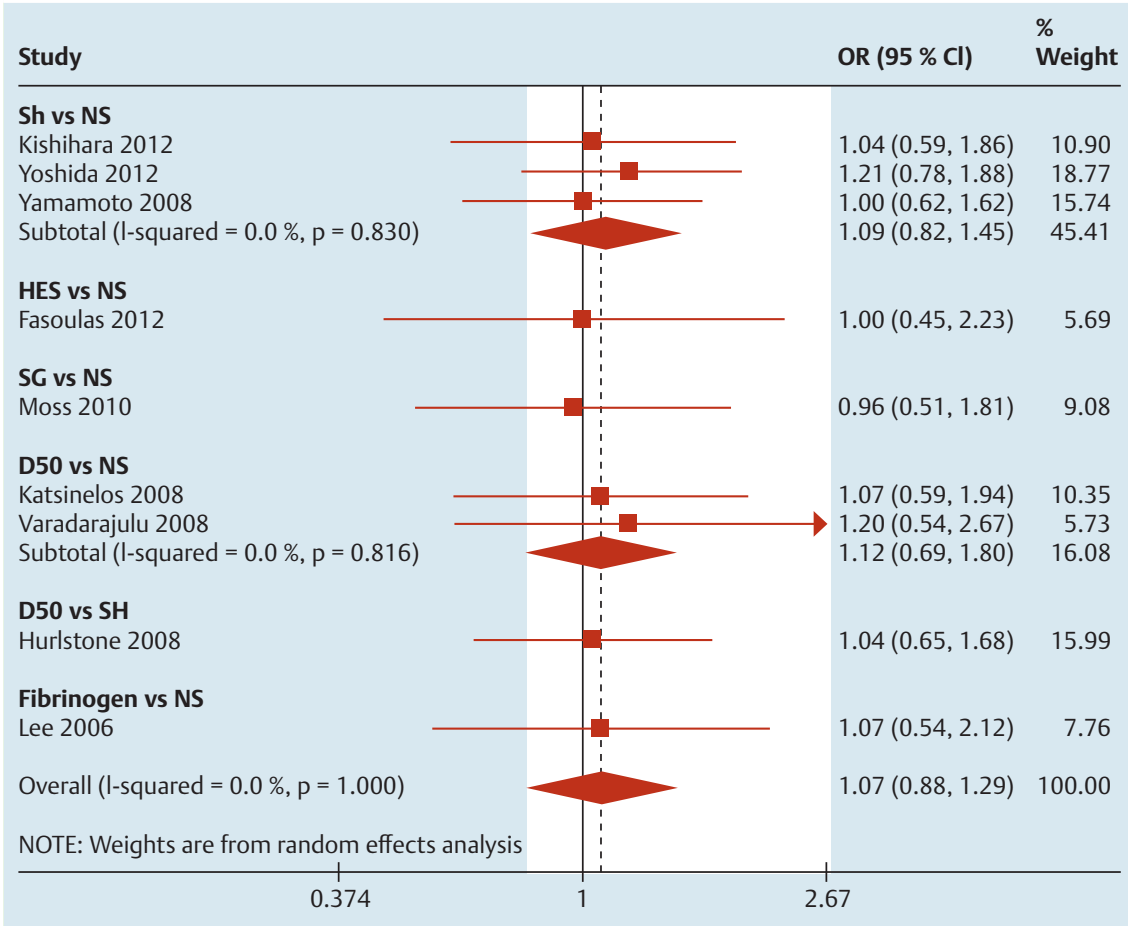

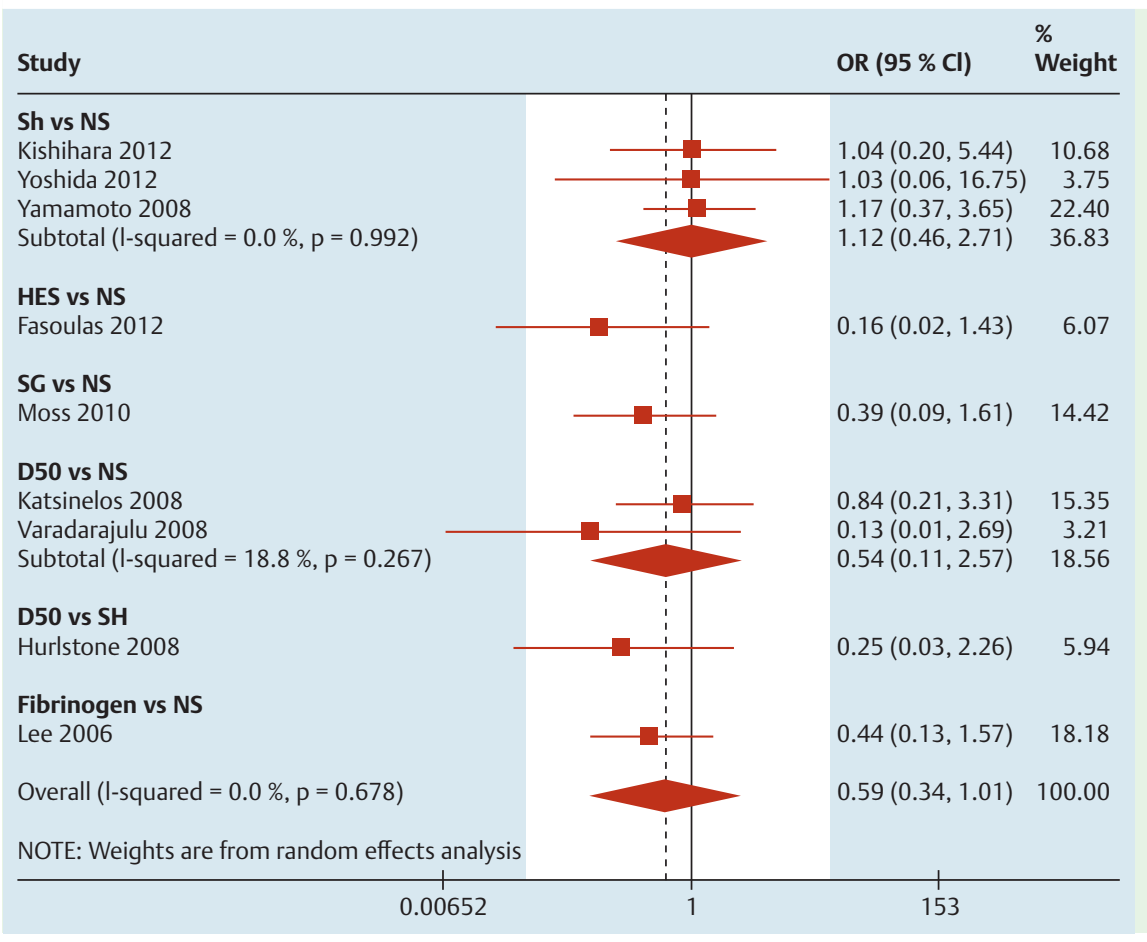

Fig. 2 Forest plot for complete resection (right side favors intervention).
Fig. 3 Forest plot for post-polypectomy bleeding (left side favors intervention). with the studies having a low heterogeneity. The results indicate that the solution used does not have a significant impact on the resection efficacy. However, most solutions were only tried in one RCT which may limit the sensitivity to detect small effects. SH is the best studied solution and was compared to NS in three RCTs (423 patients) and the pooled results fail to suggest a difference between SH and NS with OR $(95 \% \mathrm{CI}) 1.09(0.82,1.45)$. The overall plot indicates that the pooled results of the interventions (SH, HES, SG, D50, and fibrinogen) were not superior to the comparator, which was always NS with the exception of Hurlstone's trial which compared D50 to SH with OR (95\%CI) $1.07(0.88$, 1.29).

\section{Bleeding rate}

All the studies reported the post-polypectomy bleeding rate. Even though the bleeding definition was different across studies, the heterogeneity of the results was low. The pooled results are shown in Fig. 3. No single solution was shown to be more effective in decreasing the post-polypectomy bleeding rate but HES, SG, and fibrinogen have shown a non-significant favorable trend against NS with a pooled OR $(95 \% \mathrm{CI}) 0.59(0.34,1.01)$. Pooled re- 


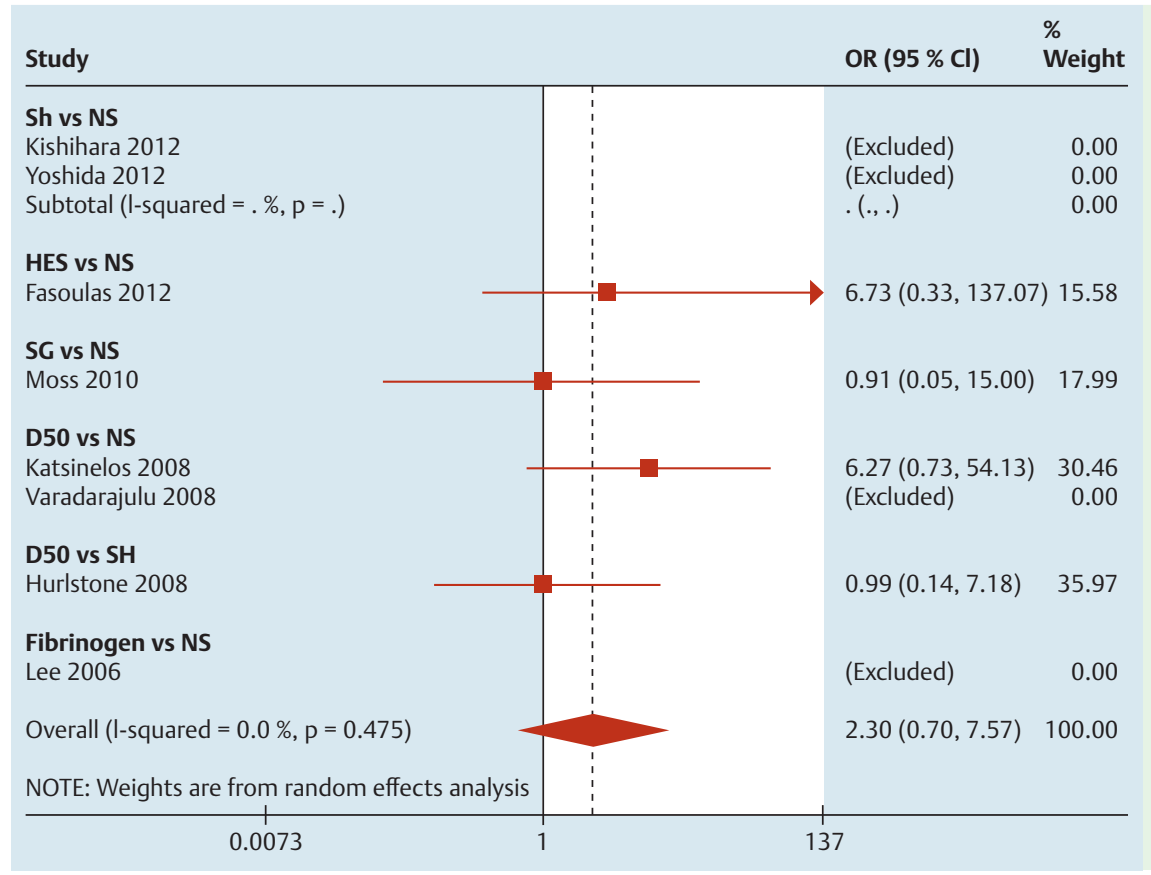

\begin{tabular}{|c|c|c|}
\hline Study & OR (95 \% Cl) & $\begin{array}{l}\% \\
\text { Weight }\end{array}$ \\
\hline $\begin{array}{l}\text { Sh vs NS } \\
\text { Kishihara } 2012 \\
\text { Yoshida } 2012\end{array}$ & $\begin{array}{l}\text { (Excluded) } \\
\text { (Excluded) }\end{array}$ & $\begin{array}{l}0.00 \\
0.00\end{array}$ \\
\hline $\begin{array}{l}\text { HES vs NS } \\
\text { Fasoulas } 2012\end{array}$ & $0.15(0.01,3.03)$ & 24.33 \\
\hline $\begin{array}{l}\text { SG vs NS } \\
\text { Moss } 2010\end{array}$ & $1.10(0.07,18.23)$ & 28.10 \\
\hline $\begin{array}{l}\text { D50 vs NS } \\
\text { Katsinelos } 2008 \\
\text { Varadarajulu } 2008\end{array}$ & $\begin{array}{l}0.16(0.02,1.38) \\
\text { (Excluded) }\end{array}$ & $\begin{array}{r}47.57 \\
0.00\end{array}$ \\
\hline $\begin{array}{l}\text { Fibrinogen vs NS } \\
\text { Lee } 2006\end{array}$ & (Excluded) & 0.00 \\
\hline $\begin{array}{l}\text { Overall }(\mathrm{l} \text {-squared }=0.0 \%, \mathrm{p}=0.506) \\
\text { NOTE: Weights are from random effects analysis }\end{array}$ & $0.27(0.06,1.19)$ & 100.00 \\
\hline 0.0073 & 137 & \\
\hline
\end{tabular}

Fig. 4 Forest plot for post-polypectomy coagulation syndrome/perforation (left side favors intervention).
Fig. 5 Forest plot for post-polypectomy coagulation syndrome/perforation with specific solutions compared with normal saline (left side favors intervention). sults for SH suggest that there is no beneficial effect on the bleeding risk when using this agent.

Post-polypectomy coagulation syndrome/perforation rate Only four studies reported the occurrence of perforations or coagulation syndrome. The results are shown in Fig. 4 . There is only one RCT for each solution and none for SH. These studies were underpowered to detect significant differences in this specific outcome but the pooled analyses seem to suggest that NS may be effective in preventing perforations and coagulation syndrome ( $\bullet$ Fig. 5$)$ with an OR $(95 \% \mathrm{CI}) 0.27(0.06,1.19)$, especially when compared to HES (OR $0.15 ; 95 \% \mathrm{CI} 0.007,3.03$ ) and D50 (OR 0.16; 95\%CI 0.02, 1.38).

\section{Other secondary end points}

Due to the lack of data and heterogeneity of definitions, it was not possible to analyze the other proposed end points, such as num- ber of submucosal injections, total volume $(\mathrm{mL})$ used, duration of submucosal cushion ( $\mathrm{min}$ ), procedural time ( $\mathrm{min}$ ), rate of en bloc resection, recurrence rate at follow-up, and incidence of tissue injury or fibrosis.

\section{Descriptive analysis}

This section will evaluate the 54 studies included in the systematic review in order to assess the proposed outcomes. A summary of these studies is available in the Appendix.

Sodium hyaluronate ( $\mathrm{SH}$ ) solution is widely used as an endoscopic submucosal injection material. It was first reported in animal models that the submucosal fluid cushion created by SH persists for longer periods of time than other available submucosal solutions [31 - 34]. Its efficacy in EMR and ESD was also reported in clinical practice. Using $0.4 \% \mathrm{SH}$ as a submucosal injection solution in endoscopic resection enabled an effective lifting of a colorectal intramucosal lesion, reducing the need for additional injec- 
tions [22]. Fujishiro et al. [35] reported that a mixture of a high concentration of SH and glycerine had good results in ESD. SH was compared with NS in two randomized controlled trials that included patients with colorectal lesion $<20 \mathrm{~mm}$ managed with EMR. Yoshida et al. [20] concluded that EMR using 0.13\% SH applied to colon lesions of less than $20 \mathrm{~mm}$ diameter is more effective than NS for complete resection and maintenance of mucosal elevation, since complete resection was achieved in 74 of 93 lesions (79.5\%) in the SH group and 63 of 96 lesions (65.6\%) in the NS group $(P<0.05)$ and high mucosal elevation was maintained in $83.9 \%$ of procedures in the $\mathrm{SH}$ group and $54.1 \%$ in the NS group $(P<0.01)$. Kishihara et al. [21] also reported the superiority of NS solution for the ease of submucosal injection and snaring with less variability $(P<0.05)$. Finally, SH was compared to NS in a randomized controlled trial with gastric lesions proposed for ESD and it was shown that the usefulness rate and the volume of solution injected were significantly better in the $0.4 \% \mathrm{SH}$ group [18]. However, SH still faces some problems, namely its higher cost, requirement of an air-sealed container for storage, and the conflicting data concerning stimulation of tumor growth [36,37]. Sodium alginate is an inexpensive high viscosity solution. Eun et al. demonstrated that mucosa-elevating capacity was comparable between $1 \%$ sodium alginate solution and $0.5 \% \mathrm{SH}$ solution [38]. It also showed greater elevation when compared to that created by NS solution [39]. In a clinical study, $0.4 \% \mathrm{SH}$ solution exhibited no significant difference in catheter injectability but significant superiority in mucosa-elevating capacity over $0.6 \%$ sodium alginate solution, with no findings indicative of tissue injury. En bloc resection was achieved in all cases, no adverse events were observed, and no case showed recurrence [40]. Further investigation is needed on the usefulness of this material as a submucosal injection solution for endoscopic procedures.

With regard to dextrose solution, in a prospective, uncontrolled clinical study, Katsinelos et al. [41] first investigated the effectiveness of EMR using a hypertonic dextrose plus epinephrine solution as a submucosal cushion agent for the resection of 59 large sessile colorectal polyps, showing that 23/59 (39\%) were resected en bloc and 36/59 (61\%) in a piecemeal fashion. Also, Varadarajulu et al. [24] compared D50 and NS for injection assisted resection of 52 sessile gastrointestinal lesions. Compared with NS, lower volumes (median 2 vs $1 \mathrm{~mL} ; P=0.03$ ) were required. Even after completion of resection, submucosal elevation persisted in $36 \%$ of the patients randomly assigned to D50 compared with $20 \%$ of those randomized to NS $(P<0.001)$. There were no significant differences in the rates of complete resection. Later, Katsinelos et al. [23] performed a prospective, double-blind, randomized study that compared EMR of 92 sessile rectosigmoid lesions (>10 mm) using D50 plus epinephrine or NS plus epinephrine. Injected solution volumes and number of injections were lower in the D50 group ( $P=0.033$ and $P=0.028$, respectively). Submucosal elevation had a longer duration in the D50 group $(P=0.043)$. This difference mainly included large $(\geq 20 \mathrm{~mm})$ and giant $(>40 \mathrm{~mm})$ lesions. There were 6 cases versus 1 case of post-polypectomy syndrome in the D50 and NS groups $(P=0.01)$. Dextrose solution was also compared with SH [19] in a RCT including 174 patients. R0 resection was achieved in 59 of the 82 lesions (72\%) in the dextrose group and in 56 of the 81 lesions (69\%) in the SH group $(P>0.1)$. Nevertheless, Fujishiro et al. [33] showed that injection of $20 \%$ submucosal dextrose in an animal model was associated with mucosal and muscle damage on the day of injection, with ulceration extending to the submucosal layer within a week after injection.
Glycerol was first evaluated for mucosal elevation in porcine esophagus, showing a longer disappearance time when compared with NS [34], and later in EMR of colorectal laterally spreading tumors (LSTs) [42]. In this clinical study, particularly for nongranular, laterally spreading tumors (LST-NGs) $<20 \mathrm{~mm}$, the glycerol group had a higher en bloc resection rate than the NS group $(P<0.01)$, however a similar recurrence rate and complications were achieved and there was no difference between en bloc resection for $\mathrm{LST} \geq 20 \mathrm{~mm}$.

Sodium carboxymethylcellulose is a water-soluble polymer derived from cellulose. In vitro, the submucosal injection of sodium carboxymethylcellulose solution was able to dissect by itself most of the mucosal layer from the muscular layer at a concentration above $2.0 \%$. In vivo, three specimens were resected with $2.5 \%$ sodium carboxymethylcellulose without difficulty. There were no procedure-related complications and histologic examination revealed no tissue damage [43].

Hydroxypropyl methylcellulose is a high viscosity agent that has been considered to be a good and low cost option readily available in the United States. Its superiority over NS solution in height and duration of mucosal elevation has been shown in animal studies [31,32]. Further studies are needed to clarify the real benefits of this synthetic agent.

Photocrosslinkable chitosan in DMEM/F12 medium is a viscous solution that crosslinks UV irradiation, resulting in an insoluble hydrogel. Photocrosslinkable chitosan hydrogel injection led to a longer lasting elevation with clearer margins compared with NS or SH solutions [44], and was useful when used in ESD [44]. Furthermore, photocrosslinkable chitosan hydrogel may contribute to the healing of artificial ulcers after EMR and ESD [45], which makes it a promising agent for endoscopic procedures and it should be evaluated in clinical trials after biocompatibility has been established.

Succinylated gelatin (SG) is a widely available, inexpensive, safe, colloidal solution that exerts an oncotic pressure comparable with that of human albumin, with a favorable safety profile. In an animal study [46], the mean EMR specimen dimension and surface area were significantly larger and the duration of mucosal elevation was significantly longer for SG $(P=0.005)$. Three perforations were recorded, two with SG and one with NS $(P=1.0)$. However, these perforations occurred in the proximal porcine colon which is thinner than distal porcine colon and human colon. The clinical efficacy of SG was evaluated by Moss et al. in a randomized double-blind trial, conducted to compare the performance of EMR with SG or NS for sessile lesions of the colon sized $\geq$ $20 \mathrm{~mm}$ [27].

The "Sydney Resection Quotient" (defined as lesion size in millimeters divided by the number of pieces to resect) was significantly different between groups, favoring SG; fewer injections per lesion $(P=0.002)$, lower injection volume $(P=0.009)$, and shorter procedure duration $(P=0.006)$ were reported with the SG group.There was also a non-significant trend towards higher en bloc resection rate with SG ( $30 \%$ vs $15 \%, P=0.137$ ). There were no perforations.

Mesna (sodium-2-mercaptoethanesulfonate $\left[\mathrm{C}_{2} \mathrm{H}_{5} \mathrm{NaO}_{3} \mathrm{~S}_{2}\right]$ ) is a mucolytic agent that acts by cleaving disulfide bonds in proteins, thereby breaking down the connective tissue between anatomical planes. A preliminary clinical study that used submucosal mesna injection for ESD demonstrated the feasibility and safety of the procedure [47]. In an animal study comparing it with NS, there were no differences between groups related to ESD procedure time and en bloc resection, but mesna injection was asso- 
ciated with a non-significant lower incidence of intraprocedural bleeding ( $P=0.09$ ) [48]. Recently, mesna solution was compared to NS in a randomized controlled trial and it showed that ESD time was not significantly different between groups, but multivariate analysis indicated that mesna reduced procedural challenges associated with submucosal dissection [17].

Autologous blood is readily available at low cost. Previous human and animal studies have demonstrated that autologous whole blood produced the longest durable cushion compared with standard agents [49]. The feasibility of EMR with blood submucosal injection was also reported with no complications $[29,50]$. Regarding tissue injury, a study has shown that blood produces less tissue injury (measured as hydrops and tears) than NS [29]. However, some potential problems need to be clarified, namely the fact that autologous blood could hamper the specialist's view during the procedure and the possibility for blood coagulation [51].

Other agents such as fibrinogen mixtures, poloxamers, and photocrosslinkable chitosan have been reported for EMR with great enthusiasm. Compared with $\mathrm{SH}$, fibrinogen mixtures and poloxamer solutions are significantly less expensive but remain substantially more expensive than NS [25]. A study that included EMR of 35 early gastric neoplasms showed that, after an initial injection of fibrinogen mixture, additional submucosal injection was not required for any lesion. The rates of en bloc resection and complete resection were, respectively, $82.9 \%$ and $88.6 \%$. The en bloc resection rate was significantly lower for lesions over 20 $\mathrm{mm}$ in diameter (60\% vs. $92 \% ; P<0.05$ ) and for lesions on the lesser curvature or posterior wall of the stomach compared with those on the greater curvature or anterior wall (55.6\% vs. $92.3 \%$; $P<0.05)$. During follow-up, recurrence was noted in only one patient in whom the lesion had been resected piecemeal [52].

Later, the clinical efficacy of the fibrinogen mixture was evaluated in a RCT, comparing it with NS in EMR of early gastric neoplasms [25]. This study did not show differences between the two groups in the rates of en bloc resection and recurrence rate, but mean procedure time was significantly shorter in the fibrinogen group and additional submucosal injection to maintain elevation of the lesion was less frequently required in the fibrinogen group $(P<0.05)$. In addition, the use of fibrinogen mixtures for endoscopic resections still needs to be critically considered with regard to their potential to transfer infections. The poloxamer solution PS137-25 was studied in porcine models, comparing it with NS and hydroxypropyl methylcellulose [53], showing greater height of the initial mucosal elevation and longer mucosal elevation. Five EMRs were successfully performed after one injection of PS137 - 25, with no thermal injury or perforations.

Recently, other alternatives have been presented. A novel injectable drug eluting elastomeric biodegradable polymer (iDEEP) was developed to overcome the limitations of previous solutions, using both viscosity and gel formation through redox initiated crosslinking [54], and showing more durable cushions than those formed with $\mathrm{NS}$ and $\mathrm{SH}$. Carbon dioxide $\left(\mathrm{CO}_{2}\right)$ was also tested as an injection agent. Uraoka et al. [55] performed an animal study that showed the safety and efficacy of $\mathrm{CO}_{2}$ as a satisfactory submucosal injection agent during ESD, the submucosal elevation created by $\mathrm{CO}_{2}$ being longer than with either NS or sodium hyaluronic acid $(P<0.001)$. Creating and maintaining a $\mathrm{CO}_{2}$ submucosal cushion of sufficient elevation was achieved combined with partial physical dissection of the submucosal layer, followed by complete endoscopic dissection of the $\mathrm{CO}_{2}$ submucosal layer with ESD, resulting in successful en bloc resection with no complications.

Cook Medical's (Bloomington, IN, United States) submucosal lifting gel consists of a proprietary combination of known biocompatible components that appears to be a promising safe and effective substance for submucosal injection. In an animal study, every injection resulted in adequate mucosal lifting, with no evidence of perforation, bleeding, gel extravasation through the serosal surface, or damage to surrounding tissue or organs [56].

\section{Discussion \\ $\nabla$}

EMR and ESD are minimally invasive endoscopic procedures now accepted worldwide as a treatment modality in the removal of dysplastic and early malignant lesions limited to the superficial layers of the gastrointestinal tract $[6,7]$. Endoscopic resection techniques are aided by mucosal elevation through the injection of a solution into the submucosal space in order to reduce complications. In this study, we tried to identify the best solution to use to lift the mucosal lesion. Our primary outcome was to evaluate complete resection of the lesion. All studies included in the meta-analysis [19-27] provided the complete resection rate. $\mathrm{SH}$ is the best studied solution, being compared with NS in three RCTs [20-22]. The remaining solutions, namely fibrinogen mixture [25], hydroxyethyl starch [26], and succinylated gelatin [27], were only studied in one RCT each. Our study shows that the available evidence does not allow a robust conclusion to be drawn on the solution's effect on resection rate (OR 1.07; 95\%CI $0.88,1.29)$ and, particularly, there is no difference between $\mathrm{SH}$ and NS (OR 1.09; 95\%CI 0.82, 1.45) ( $\bullet$ Fig.3).

Regarding the complications, bleeding rate was reported in all studies, but the definition of bleeding was different across studies. We found that no single solution was shown to be more effective in decreasing the post-polypectomy bleeding rate, but HES, SG, and fibrinogen have shown a non-significant favorable trend against NS. The post-polypectomy coagulation syndrome/perforation rate was evaluated in four studies [19,23,26,27]. From the analysis, we infer that NS may have a beneficial effect in preventing perforations and coagulation syndrome ( $\bullet$ Fig.5) with an OR $(95 \% \mathrm{CI}) 0.27(0.06,1.19)$, especially when compared to HES (OR 0.15; 95\%CI 0.007, 3.03) and D50 (OR 0.16; 95\%CI 0.02, 1.38). However, these are rare events and a much larger sample size would be needed to determine a more precise effect estimate.

In the descriptive analysis section, we analyzed several solutions with different properties. Many solutions have been tested in animal studies and most seem more effective for mucosal elevation than NS, without significant differences in complication rates. We highlight that the superiority of these solutions must be evaluated in RCTs.

According to our results, no solution was proven to be superior in complete resection rate, post-polypectomy bleeding, or coagulation syndrome/perforation incidence. We emphasize the need for continuing research in this topic.

\section{Potential biases and limitations}

Our conclusions are limited by the small number of published RCTs and because there are several solutions being evaluated and different control groups.

There is a potential bias in the analysis as many studies were not clear as to whether they report the intention-to-treat (ITT) or the 
per protocol analysis. Also two of the RCTs were not adequately blinded. The studies include lesions in the stomach, in the colon or rectum, and the effect of the submucosal injection may be different according to the anatomical site. In addition, the size of the lesions was quite different between studies, ranging from $8.5 \mathrm{~mm}$ to $46 \mathrm{~mm}$ lesions (EMR studies) and this represents a heterogeneous sample to pool.

We chose to consider complete resection as either endoscopic or histologically assessed in the original studies even though they may not be perfectly correlated. In the adverse event reporting, there were also a wide range of definitions for post-polypectomy bleeding and some of the studies reported immediate and/or delayed bleeding rates, while we counted the totals.

\section{Conclusions}

$\nabla$

In summary, there are many solutions being commonly used for submucosal injection and many more under research. There is a lack of high quality evidence. According to the present meta-analysis, it is not possible to select one solution over the others by considering complete resection rates and procedural safety. There was a trend towards a higher risk of bleeding and a lower risk of perforation/post-polypectomy syndrome with NS.

More trials may be needed to select the best solution. At the moment, RCTs should use NS as the control group.

Competing interests: None of the authors has any relevant conflict of interest to disclose.

Institutions

${ }^{1}$ Department of Gastroenterology, Hospital Beatriz Ângelo, Lisboa, Portugal 2 Department of Gastroenterology, Instituto Português do Oncologia de Lisboa, Lisboa, Portugal

Department of Gastroenterology, Instituto Português do Oncologia do Porto, Porto, Portuga

${ }^{4}$ CIDES/CINTESIS, Faculty of Medicine - University of Porto, Porto, Portugal

\section{References}

1 Ferlay J, Shin HR, Bray F et al. Estimates of worldwide burden of cancer in 2008: GLOBOCAN 2008. Int J Cancer 2010; 127: 2893-2917

2 Zauber AG, Winawer SJ, O'Brien MJ et al. Colonoscopic polypectomy and long-term prevention of colorectal-cancer deaths. NEJM 2012; 366: 687-696

3 Winawer SJ, Zauber AG, Ho MN et al. Prevention of colorectal cancer by colonoscopic polypectomy. The National Polyp Study Workgroup. NEJM 1993; 329: 1977-1981

4 Hartgrink HH, Jansen EP, van Grieken NC et al. Gastric cancer. Lancet 2009; 374: 477 - 490

5 Ajani JA, Bentrem DJ, Besh S et al. Gastric cancer, version 2. 2013: featured updates to the NCCN Guidelines. J Natl Compr Canc Netw 2013; 11: $531-546$

6 Isomoto H, Shikuwa S, Yamaguchi N et al. Endoscopic submucosal dissection for early gastric cancer: a large-scale feasibility study. Gut 2009: 58: 331 - 336

7 Choi KS, Jung HY, Choi KD et al. EMR versus gastrectomy for intramucosal gastric cancer: comparison of long-term outcomes. Gastrointest Endosc 2011; 73: $942-948$

8 Rosenberg $N$. Submucosal saline wheal as safety factor in fulguration or rectal and sigmoidal polypi. AMA Arch Surg 1955; 70: 120-122

9 Deyhle P, Jenny S, Fumagalli I. [Endoscopic polypectomy in the proximal colon. A diagnostic, therapeutic (and preventive?) intervention] Dtsch Med Wochenschr 1973; 98: 219-220

10 Akiyama $M$, Ota $M$, Nakajima $H$ et al. Endoscopic mucosal resection of gastric neoplasms using a ligating device. Gastrointest Endosc 1997; 45: $182-186$
11 Inoue $H$, Takeshita $K$, Hori $H$ et al. Endoscopic mucosal resection with a cap-fitted panendoscope for esophagus, stomach, and colon mucosal lesions. Gastrointest Endosc 1993; 39: 58 -62

12 Kantsevoy SV, Adler DG, Conway JD et al. Endoscopic mucosal resection and endoscopic submucosal dissection. Gastrointest Endosc 2008; 68: $11-18$

13 Moss A, Bourke MJ, Williams SJ et al. Endoscopic mucosal resection outcomes and prediction of submucosal cancer from advanced colonic mucosal neoplasia. Gastroenterology 2011; 140: 1909-1918

14 Park YM, Cho E, Kang HY et al. The effectiveness and safety of endoscopic submucosal dissection compared with endoscopic mucosal resection for early gastric cancer: a systematic review and metaanalysis. Surg Endosc 2011; 25: 2666-2677

15 Lian J, Chen S, Zhang Y et al. A meta-analysis of endoscopic submucosal dissection and EMR for early gastric cancer. Gastrointest Endosc 2012 . 76: $763-770$

16 Cao Y, Liao C, Tan A et al. Meta-analysis of endoscopic submucosal dissection versus endoscopic mucosal resection for tumors of the gastrointestinal tract. Endoscopy 2009; 41: 751 - 757

17 Sumiyama K, Toyoizumi H, Ohya TR et al. A double-blind, block-randomized, placebo-controlled trial to identify the chemical assistance effect of mesna submucosal injection for gastric endoscopic submucosal dissection. Gastrointest Endosc 2014; 79: 756-764

18 Kim YD, Lee J, Cho JY et al. Efficacy and safety of 0.4 percent sodium hyaluronate for endoscopic submucosal dissection of gastric neoplasms. World J Gastroenterol 2013; 19: 3069 - 3076

19 Hurlstone DP, Fu KI, Brown SR et al. EMR using dextrose solution versus sodium hyaluronate for colorectal Paris type I and 0-II lesions: a randomized endoscopist-blinded study. Endoscopy 2008; 40: 110-114

20 Yoshida N, Naito $Y$, Inada $Y$ et al. Endoscopic mucosal resection with $0.13 \%$ hyaluronic acid solution for colorectal polyps less than $20 \mathrm{~mm}$ : a randomized controlled trial. J Gastroenterol Hepatol 2012; 27: $1377-1383$

21 Kishihara T, Chino A, Uragami N et al. Usefulness of sodium hyaluronate solution in colorectal endoscopic mucosal resection. Dig Endosc 2012; 24: $348-352$

22 Yamamoto H, Yahagi N, Oyama T et al. Usefulness and safety of $0.4 \%$ sodium hyaluronate solution as a submucosal fluid "cushion" in endoscopic resection for gastric neoplasms: a prospective multicenter trial. Gastrointest Endosc 2008; 67: 830-839

23 Katsinelos P, Kountouras J, Paroutoglou G et al. A comparative study of $50 \%$ dextrose and normal saline solution on their ability to create submucosal fluid cushions for endoscopic resection of sessile rectosigmoid polyps. Gastrointest Endosc 2008; 68: 692-698

24 Varadarajulu S, Tamhane A, Slaughter RL. Evaluation of dextrose $50 \%$ as a medium for injection-assisted polypectomy. Endoscopy 2006; 38 : 907-912

25 Lee SH, Park JH, do Park H et al. Clinical efficacy of EMR with submucosal injection of a fibrinogen mixture: a prospective randomized trial. Gastrointest Endosc 2006; 64: 691-696

26 Fasoulas $K$, Lazaraki G, Chatzimavroudis $G$ et al. Endoscopic mucosal resection of giant laterally spreading tumors with submucosal injection of hydroxyethyl starch: comparative study with normal saline solution. Surg Laparosc Endosc Percutan Tech 2012; 22: 272 - 278

27 Moss A, Bourke MJ, Metz AJ. A randomized, double-blind trial of succinylated gelatin submucosal injection for endoscopic resection of large sessile polyps of the colon. Am J Gastroenterol 2010; 105: 2375 - 2382

28 Lee SH, Chung IK, Kim SJ et al. Comparison of postpolypectomy bleeding between epinephrine and saline submucosal injection for large colon polyps by conventional polypectomy: a prospective randomized, multicenter study. World J Gastroenterol 2007; 13: 2973-2977

29 Wen $W$, Shi C, Shi Yet al. A pilot animal and clinical study of autologous blood solution compared with normal saline for use as an endoscopic submucosal cushion. Exp Ther Med 2012; 4: 419-424

30 Dobrowolski S, Dobosz M, Babicki A et al. Prophylactic submucosal saline-adrenaline injection in colonoscopic polypectomy: prospective randomized study. Surg Endosc 2004; 18: 990-993

31 Polymeros $D$, Kotsalidis $G$, Triantafyllou $K$ et al. Comparative performance of novel solutions for submucosal injection in porcine stomachs: An ex vivo study. Dig Liver Dis 2010; 42: 226-229

32 Hyun JJ, Chun HR, Chun HJ et al. Comparison of the characteristics of submucosal injection solutions used in endoscopic mucosal resection. Scand J Gastroenterol 2006; 41: 488 - 492 
33 Fujishiro $M$, Yahagi $N$, Kashimura $K$ et al. Tissue damage of different submucosal injection solutions for EMR. Gastrointest Endosc 2005; 62: $933-942$

34 Conio M, Rajan E, Sorbi D et al. Comparative performance in the porcine esophagus of different solutions used for submucosal injection. Gastrointest Endosc 2002; 56: 513-516

35 Fujishiro M, Yahagi N, Nakamura $M$ et al. Successful outcomes of a novel endoscopic treatment for GI tumors: endoscopic submucosal dissection with a mixture of high-molecular-weight hyaluronic acid, glycerin, and sugar. Gastrointest Endosc 2006; 63: 243-249

36 Sohn DK, Chang HJ, Choi HS et al. Does hyaluronic acid stimulate tumor growth after endoscopic mucosal resection? J Gastroenterol Hepatol 2008; 23: $1204-1207$

37 Matsui Y, Inomata M, Izumi $\mathrm{K}$ et al. Hyaluronic acid stimulates tumorcell proliferation at wound sites. Gastrointest Endosc 2004; 60: 539 543

38 Eun SH, Cho JY, Jung IS et al. Effectiveness of sodium alginate as a submucosal injection material for endoscopic mucosal resection in animal. Gut Liver 2007; 1: 27 - 32

39 Akagi $T$, Yasuda $K$, Tajima $M$ et al. Sodium alginate as an ideal submucosal injection material for endoscopic submucosal resection: preliminary experimental and clinical study. Gastrointest Endosc 2011; 74: $1026-1032$

40 Kusano T, Etoh T, Akagi T et al. Evaluation of $0.6 \%$ sodium alginate as a submucosal injection material in endoscopic submucosal dissection for early gastric cancer. Dig Endosc 2014; 26: 638-645

41 Katsinelos P, Paroutoglou G, Beltsis A et al. Endoscopic mucosal resection of lateral spreading tumors of the colon using a novel solution. Surg Laparosc Endosc Percutan Tech 2006; 16: 73 - 77

42 Uraoka T, Fujii T, Saito Y et al. Effectiveness of glycerol as a submucosal injection for EMR. Gastrointest Endosc 2005; 61: 736 - 740

43 Yamasaki M, Kume K, Yoshikawa I et al. A novel method of endoscopic submucosal dissection with blunt abrasion by submucosal injection of sodium carboxymethylcellulose: an animal preliminary study. Gastrointest Endosc 2006; 64: 958-965

44 Kumano I, Ishihara M, Nakamura $S$ et al. Endoscopic submucosal dissection for pig esophagus by using photocrosslinkable chitosan hydrogel as submucosal fluid cushion. Gastrointest Endosc 2012; 75: 841 848

45 Hayashi T, Matsuyama T, Hanada K et al. Usefulness of photocrosslinkable chitosan for endoscopic cancer treatment in alimentary tract. J Biomed Mater Res B Appl Biomater 2004; 71: 367-372
46 Moss A, Bourke MJ, Kwan V et al. Succinylated gelatin substantially increases en bloc resection size in colonic EMR: a randomized, blinded trial in a porcine model. Gastrointest Endosc 2010; 71: 589-595

47 Sumiyama K, Tajiri $H$, Gostout CJ et al. Chemically assisted submucosal injection facilitates endoscopic submucosal dissection of gastric neoplasms. Endoscopy 2010; 42: 627-632

48 von Renteln D, Dulai PS, Pohl H et al. Endoscopic submucosal dissection with a flexible Maryland dissector: randomized comparison of mesna and saline solution for submucosal injection (with videos). Gastrointest Endosc 2011; 74: 906 - 911

49 Giday SA, Magno P, Buscaglia JM et al. Is blood the ideal submucosal cushioning agent? A comparative study in a porcine model Endoscopy 2006; $38: 1230-1234$

50 Sato $T$. A novel method of endoscopic mucosal resection assisted by submucosal injection of autologous blood (blood patch EMR). Dis Colon Rectum 2006; 49: 1636-1641

51 Al-Taie $\mathrm{OH}$, Bauer Y, Dietrich CG et al. Efficacy of submucosal injection of different solutions inclusive blood components on mucosa elevation for endoscopic resection. Clin Exp Gastroenterol 2012; 5: 43 - 48

52 Lee SH, Cho WY, Kim HJ et al. A new method of EMR: submucosal injection of a fibrinogen mixture. Gastrointest Endosc 2004; 59: 220 - 224

53 Fernandez-Esparrach G, Shaikh SN, Cohen A et al. Efficacy of a reversephase polymer as a submucosal injection solution for EMR: a comparative study (with video). Gastrointest Endosc 2009; 69: 1135-1139

54 Tran RT, Palmer M, Tang SJ et al. Injectable drug-eluting elastomeric polymer: a novel submucosal injection material. Gastrointest Endosc 2012; 75: $1092-1097$

55 Uraoka T, Kawahara Y, Ohara N et al. Carbon dioxide submucosal injection cushion: an innovative technique in endoscopic submucosal dissection. Dig Endosc 2011; 23: 5-9

56 Chandrasekhara V, Sigmon JCJr, Surti VC et al. A novel gel provides durable submucosal cushion for endoscopic mucosal resection and endoscopic submucosal dissection. Surg Endosc 2013; 27: 3039-3042

57 Yoshida $N$, Naito $Y$, Kugai $M$ et al. Efficacy of hyaluronic acid in endoscopic mucosal resection of colorectal tumors. J Gastroenterol Hepatol 2011; 26: 286-291

58 Ishizuka T, Ishihara M, Aiko $S$ et al. Experimental evaluation of photocrosslinkable chitosan hydrogel as injection solution for endoscopic resection. Endoscopy 2009; 41: 25 - 28 


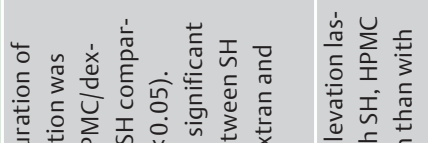

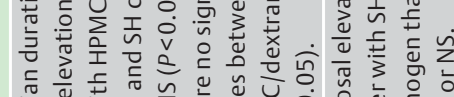

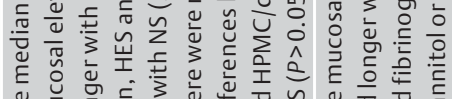

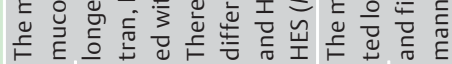
 $\sqrt{2}$
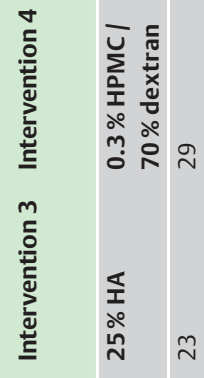

กั
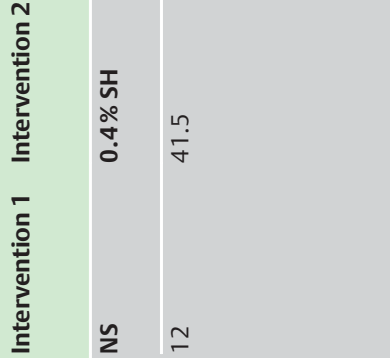

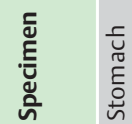

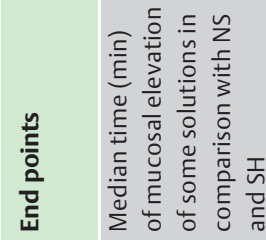

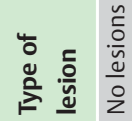

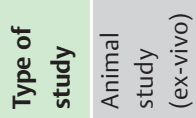

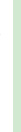

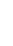

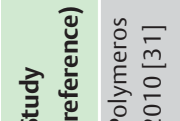

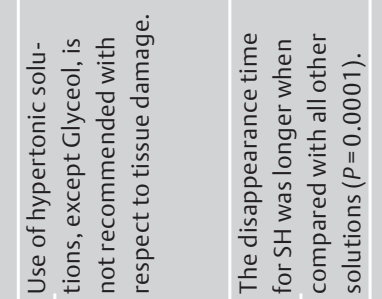

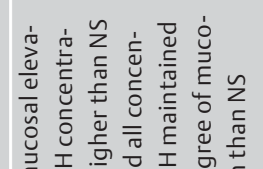

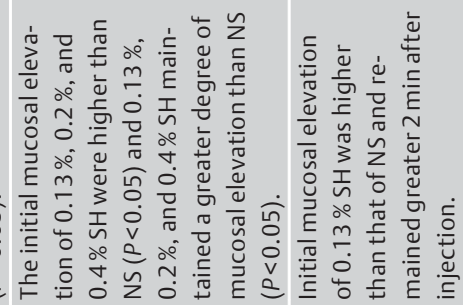

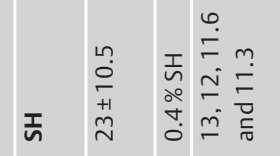

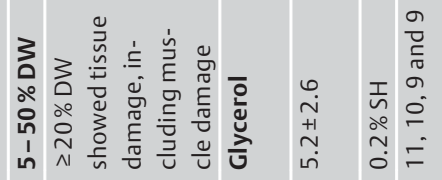

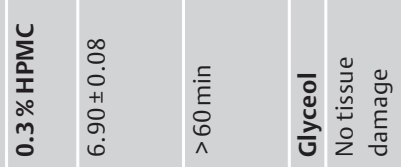

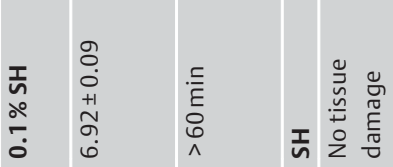

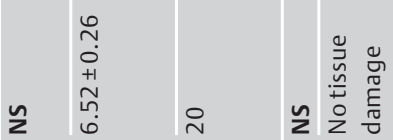

$\frac{\text { 흥 }}{2}$

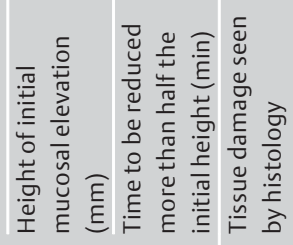

$\frac{n}{\frac{n}{0}}$

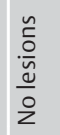

高部

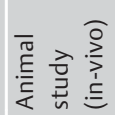

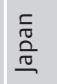

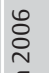

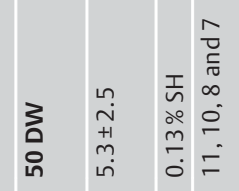

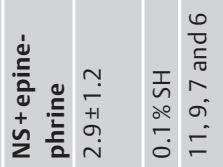

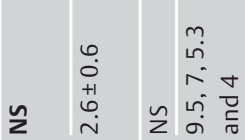

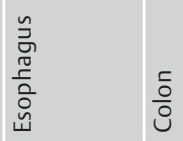

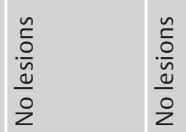

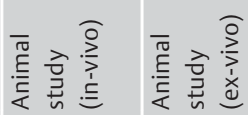

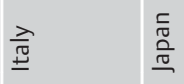

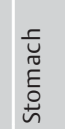

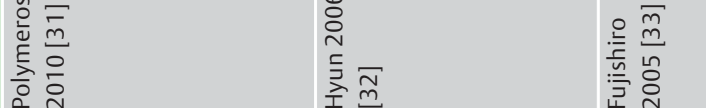

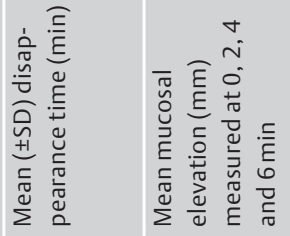

\begin{tabular}{|c|c|c|}
\hline $\begin{array}{l}\text { J̃ } \\
\underline{\underline{0}}\end{array}$ & $\begin{array}{l}\frac{c}{0} \\
\frac{0}{0} \\
\frac{0}{0}\end{array}$ & $\frac{\lambda}{\mathbb{N}}$ \\
\hline 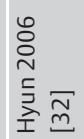 & 을 $\frac{\bar{m}}{\frac{m}{m}}$ & 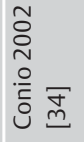 \\
\hline
\end{tabular}

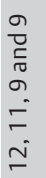

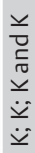

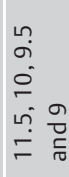

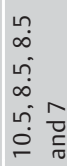

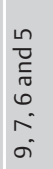

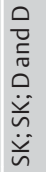

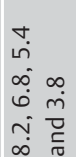

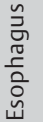

$\frac{\check{0}}{\mathrm{o}}$

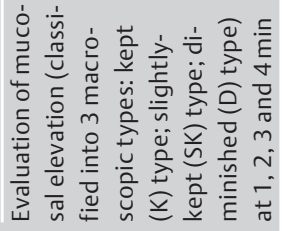

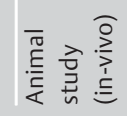




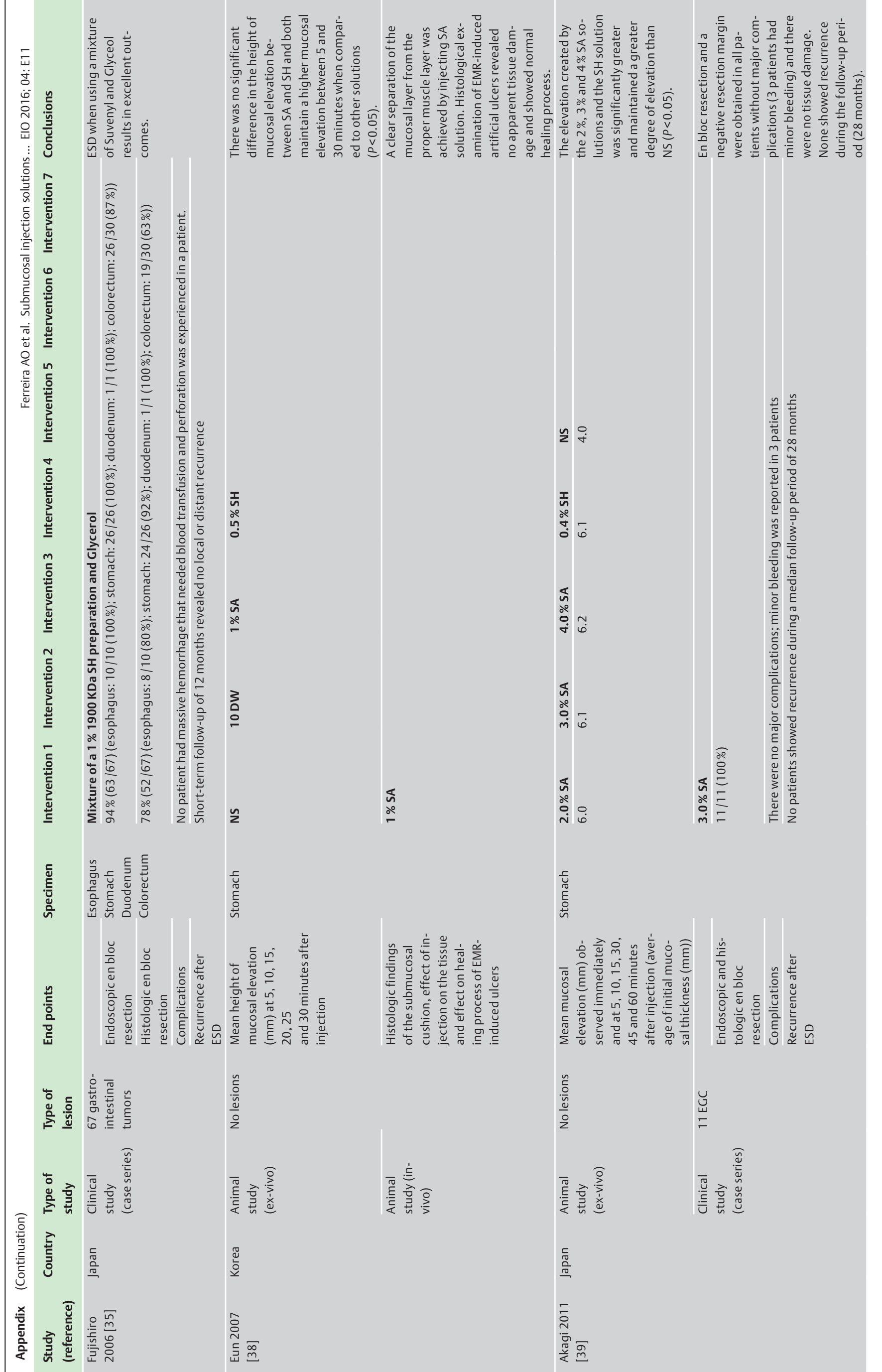




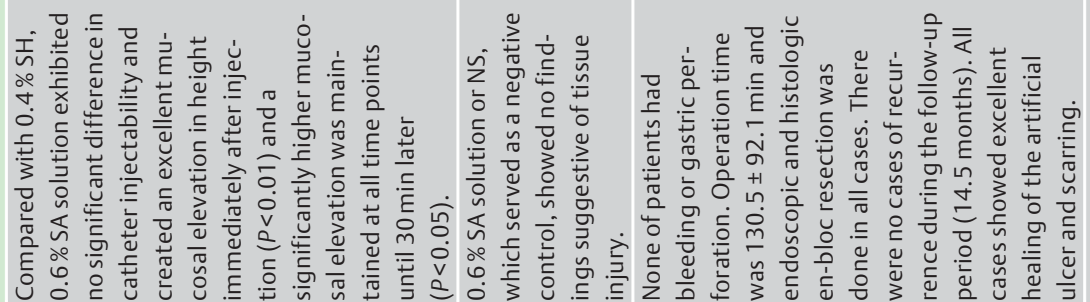

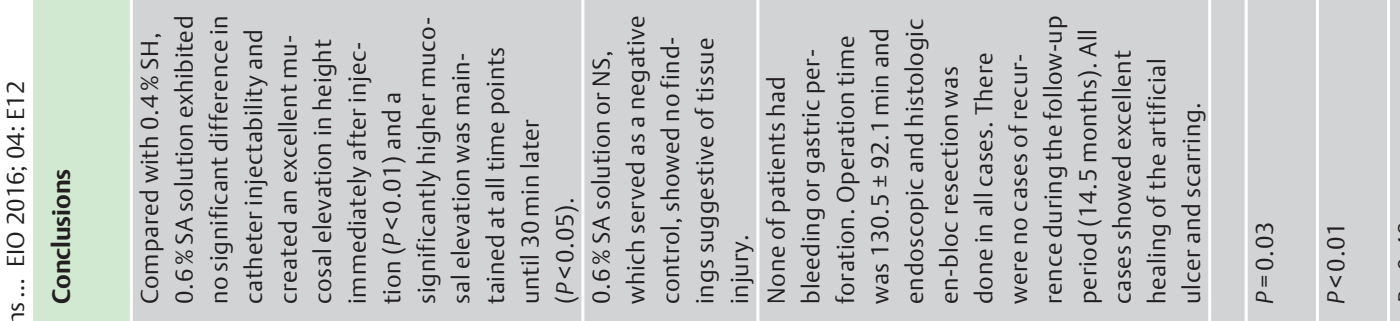

.
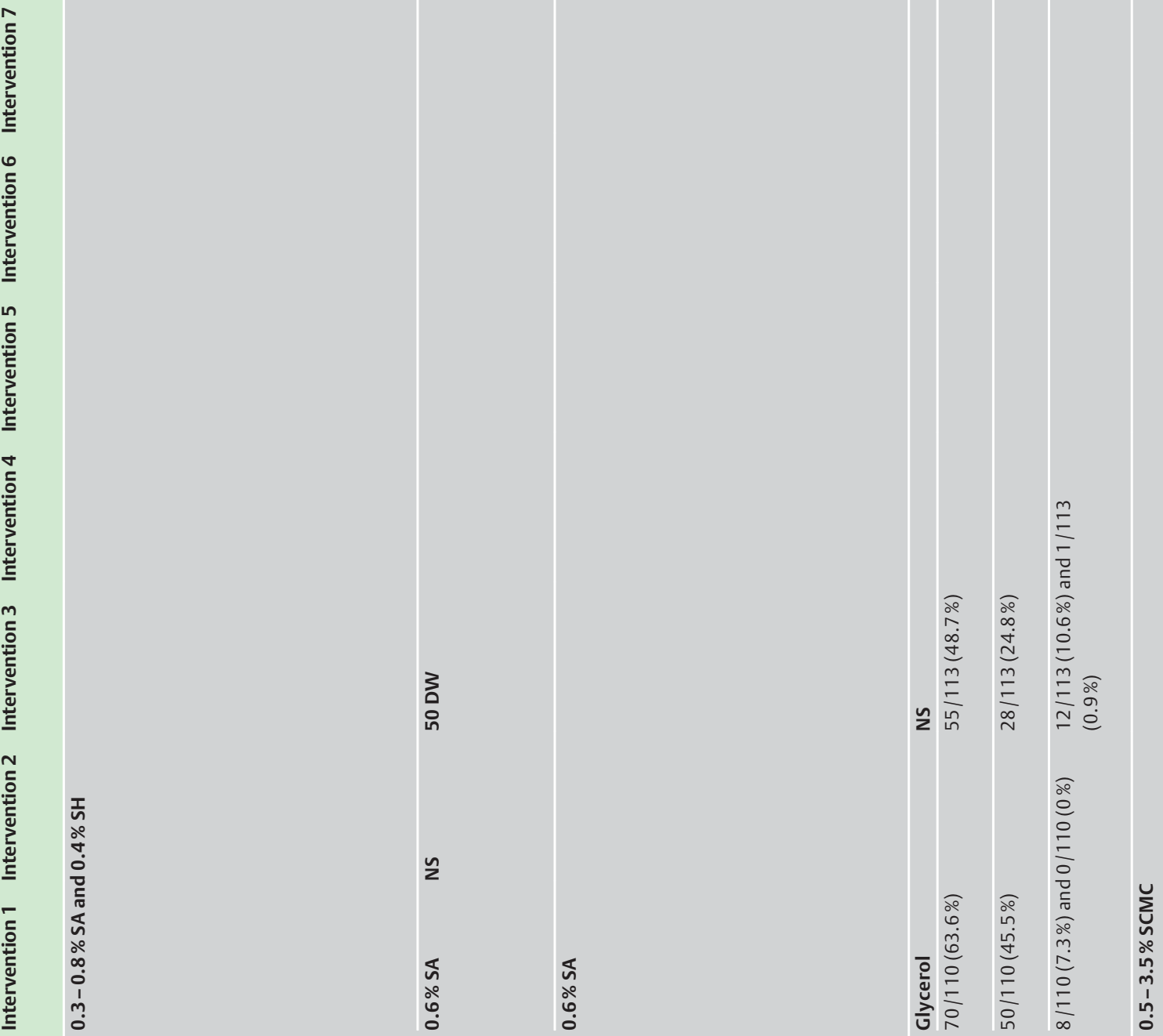

II

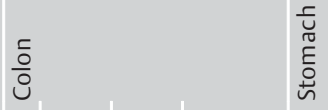

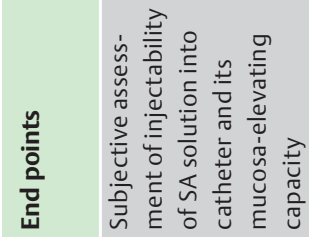

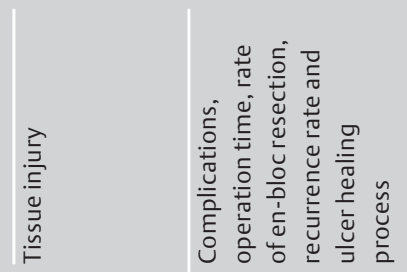

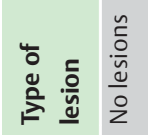

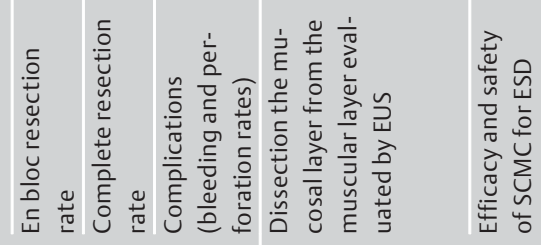

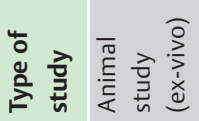

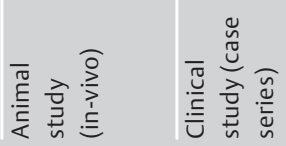

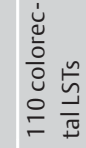

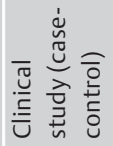

$\sum_{u}^{u}$
ஸें
in

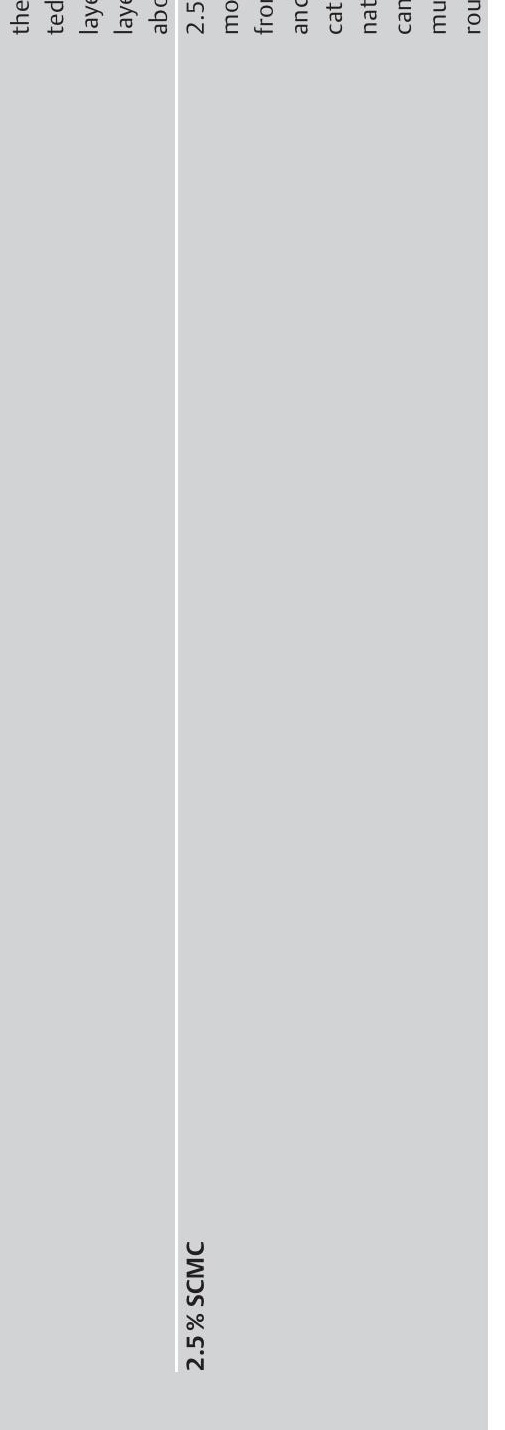

.

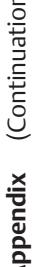

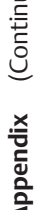

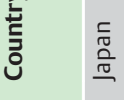

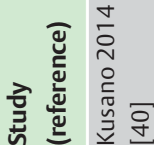

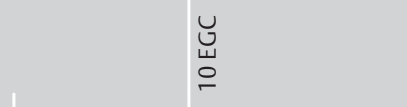

$\frac{\tilde{c}}{\frac{n}{y}}$

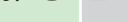

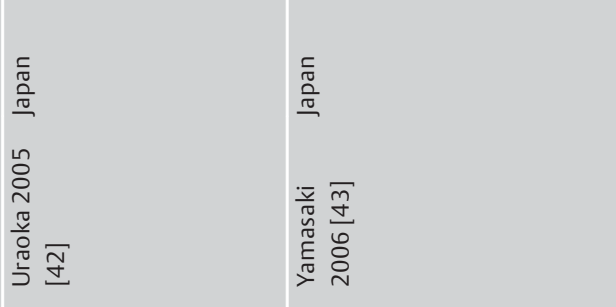




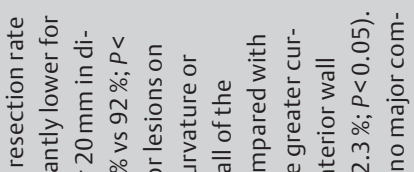

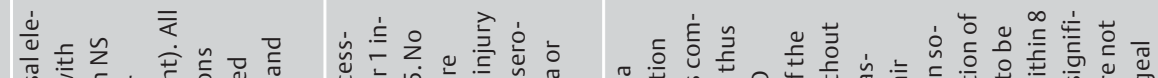

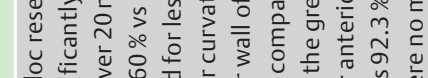

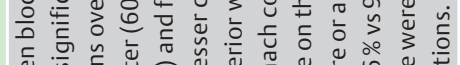

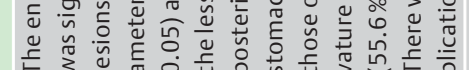

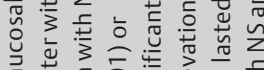

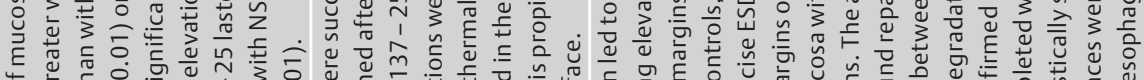

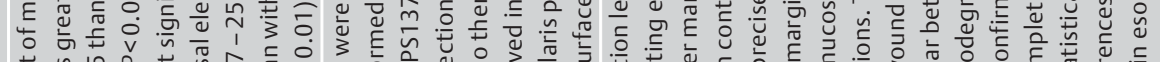

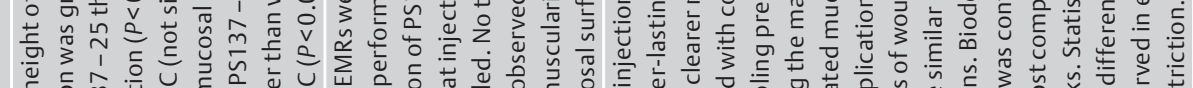
Wำำ

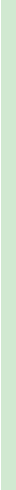

(1)

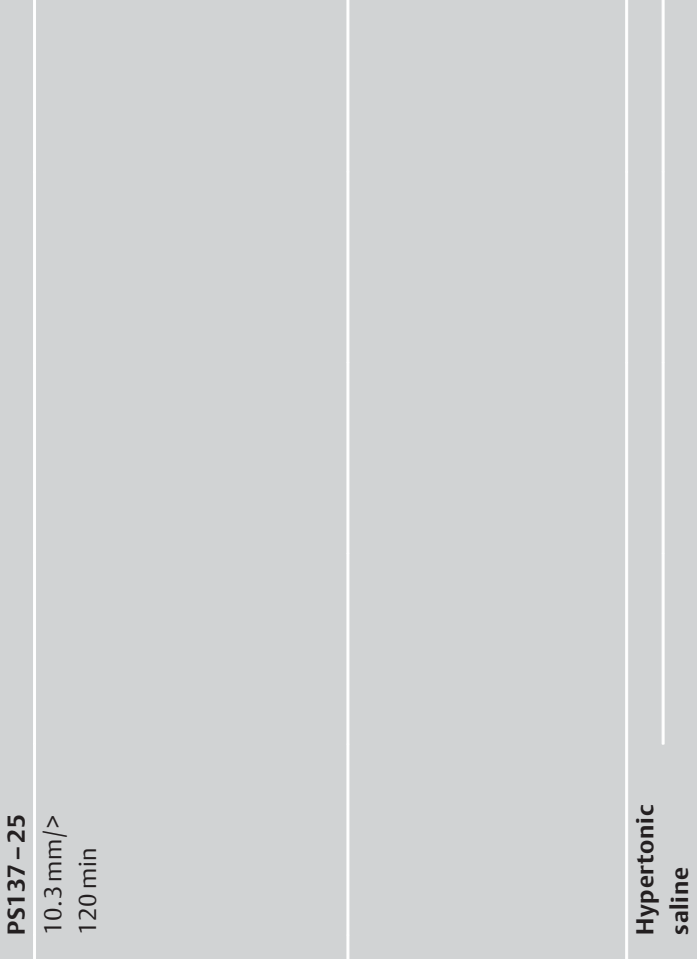

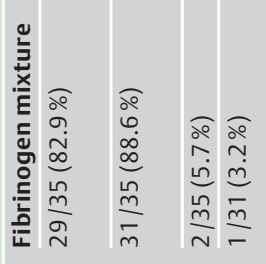

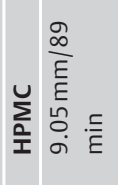

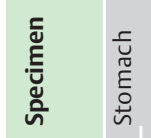

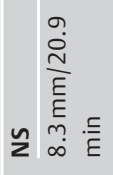

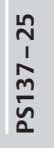

エ

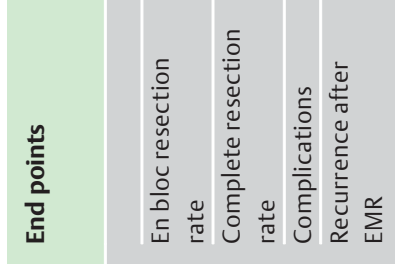

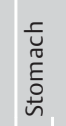

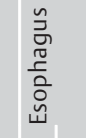

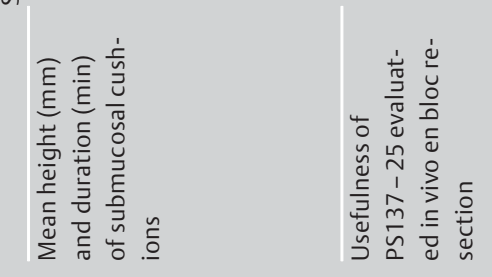

ฐ

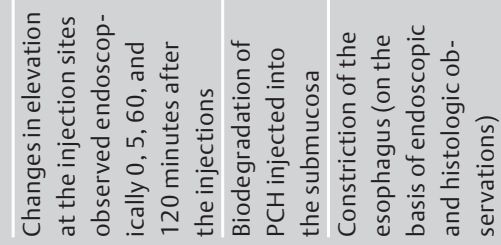

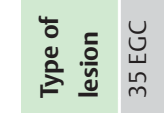

$\frac{n}{\frac{n}{n}}$

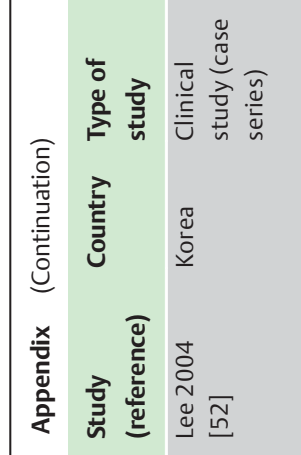

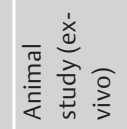

高旁旁亭

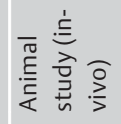

$\overleftarrow{5}$

$\frac{\sqrt{0}}{\sqrt{0}}$

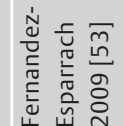

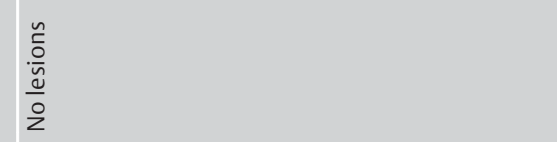

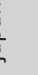




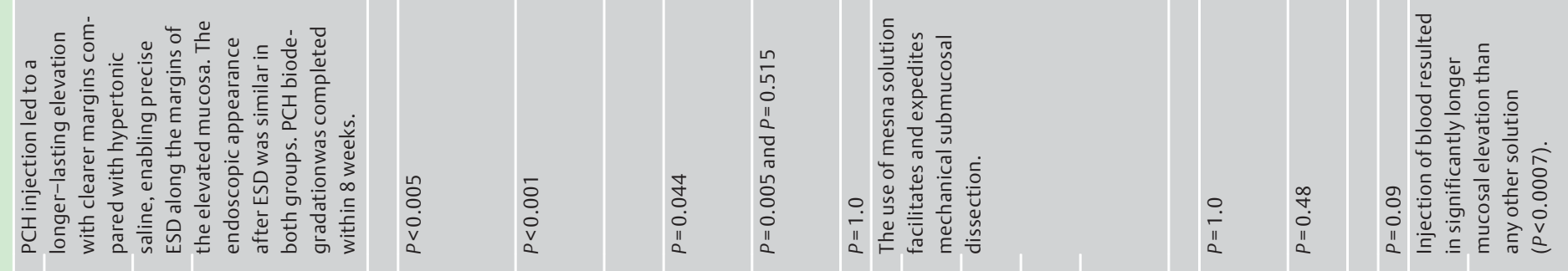



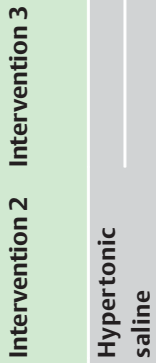

İ

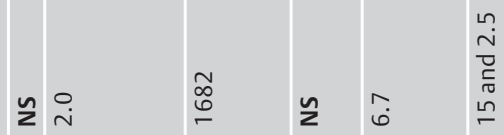

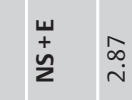

竞

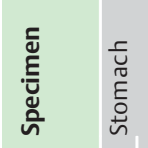

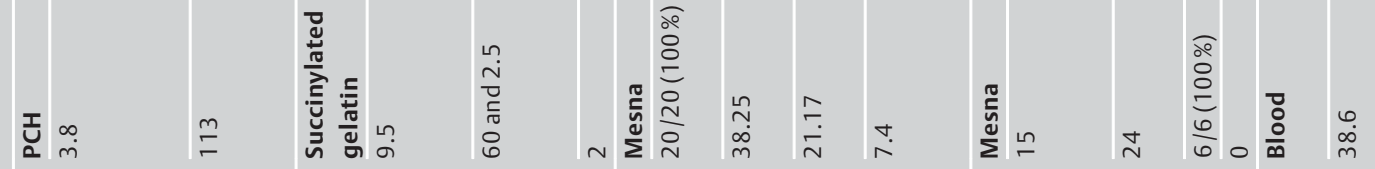

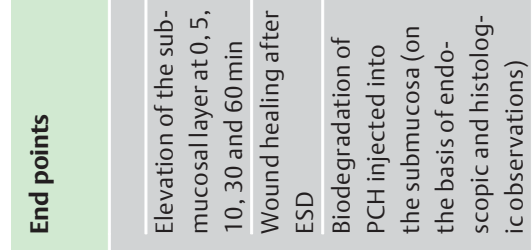

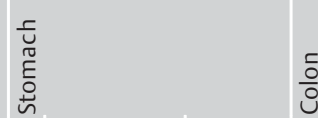

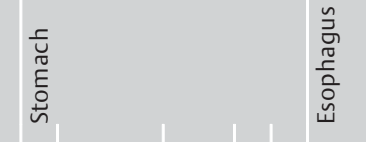

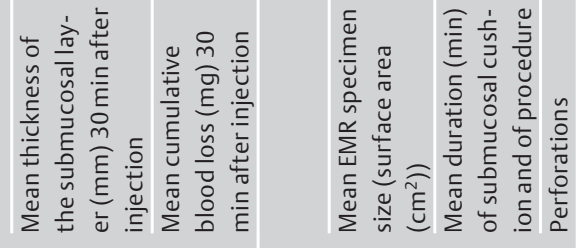

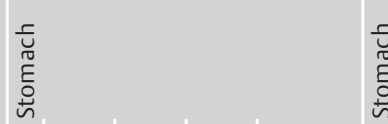

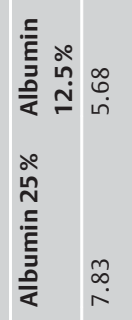

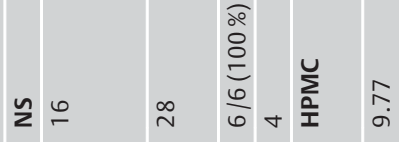

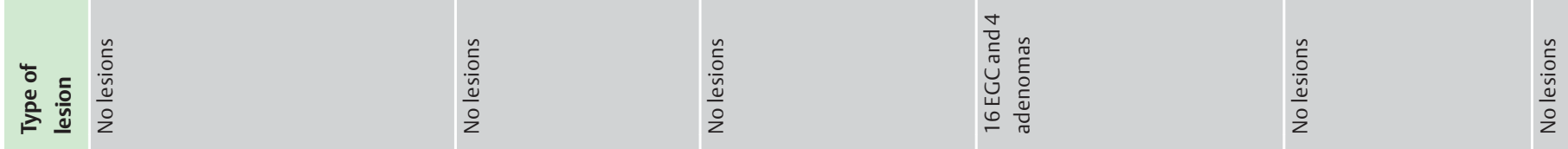

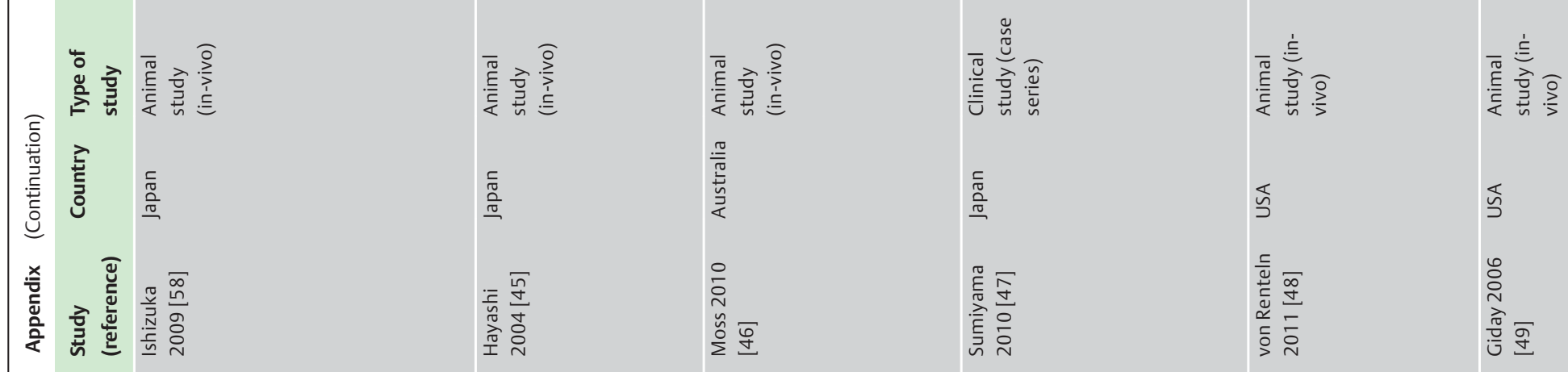




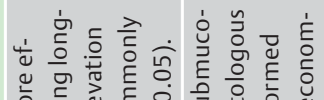

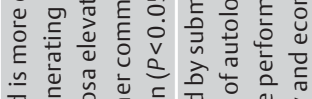

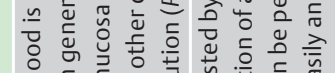

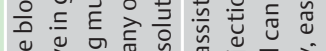

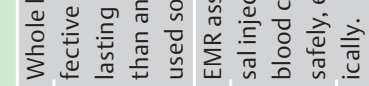

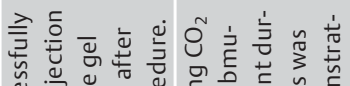

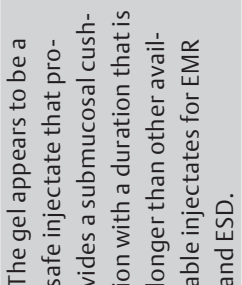

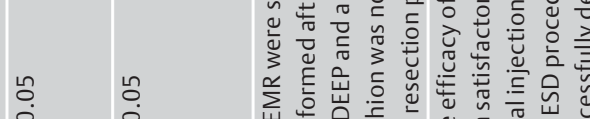

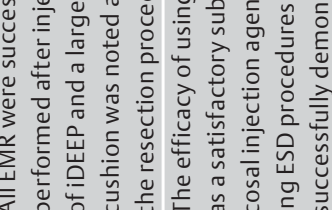

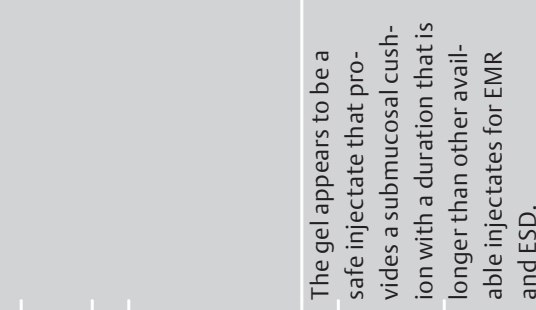

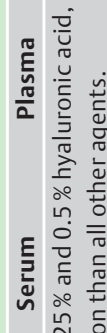

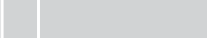

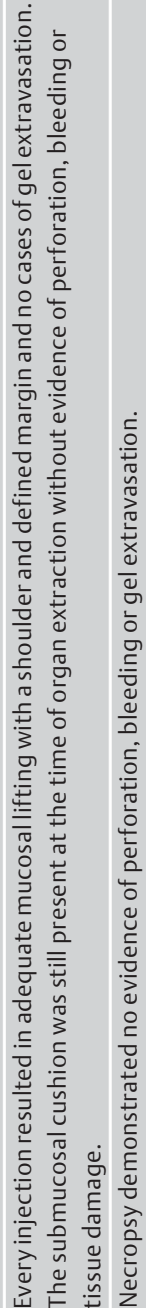

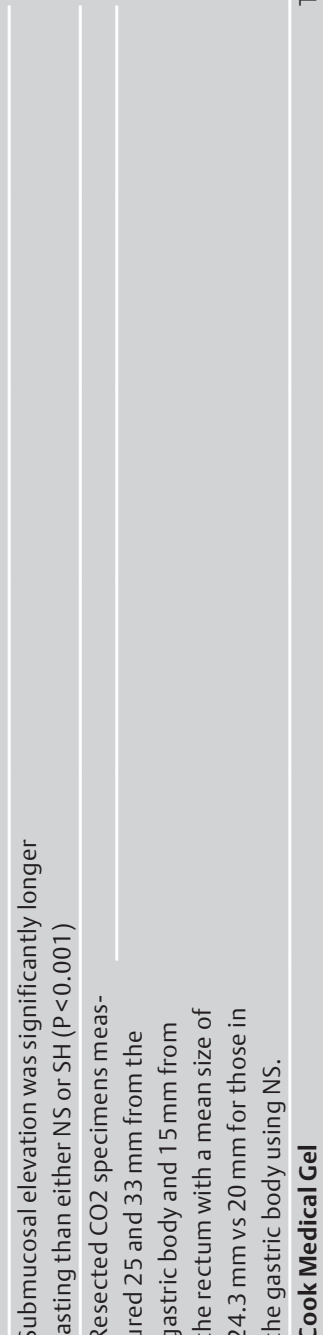

$\frac{z}{\stackrel{i}{ \pm}}$

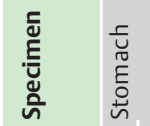

흥

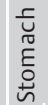

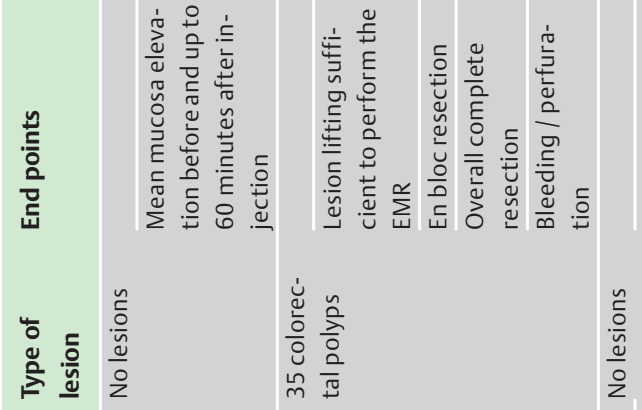

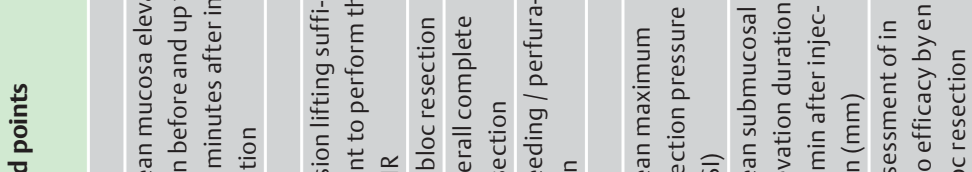

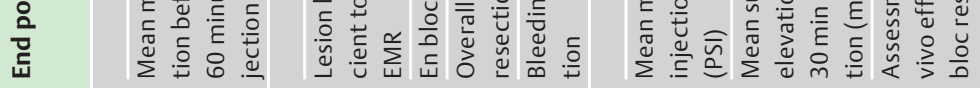

总

즌

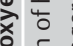

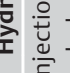

-

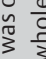

ก เ

ชิ

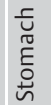

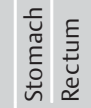

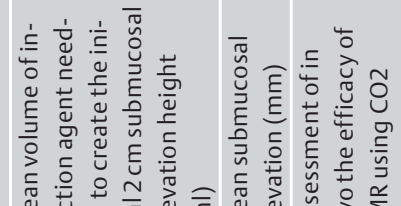

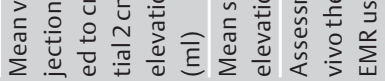

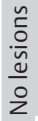

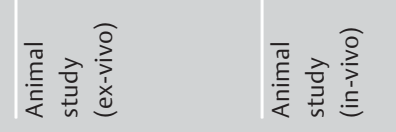

鲁

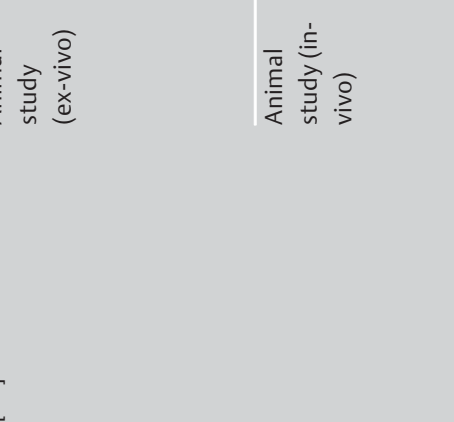

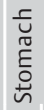

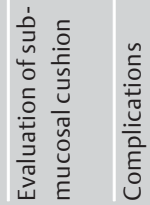

$\frac{n}{\frac{\tilde{c}}{n}}$

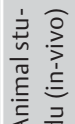

芩

它 


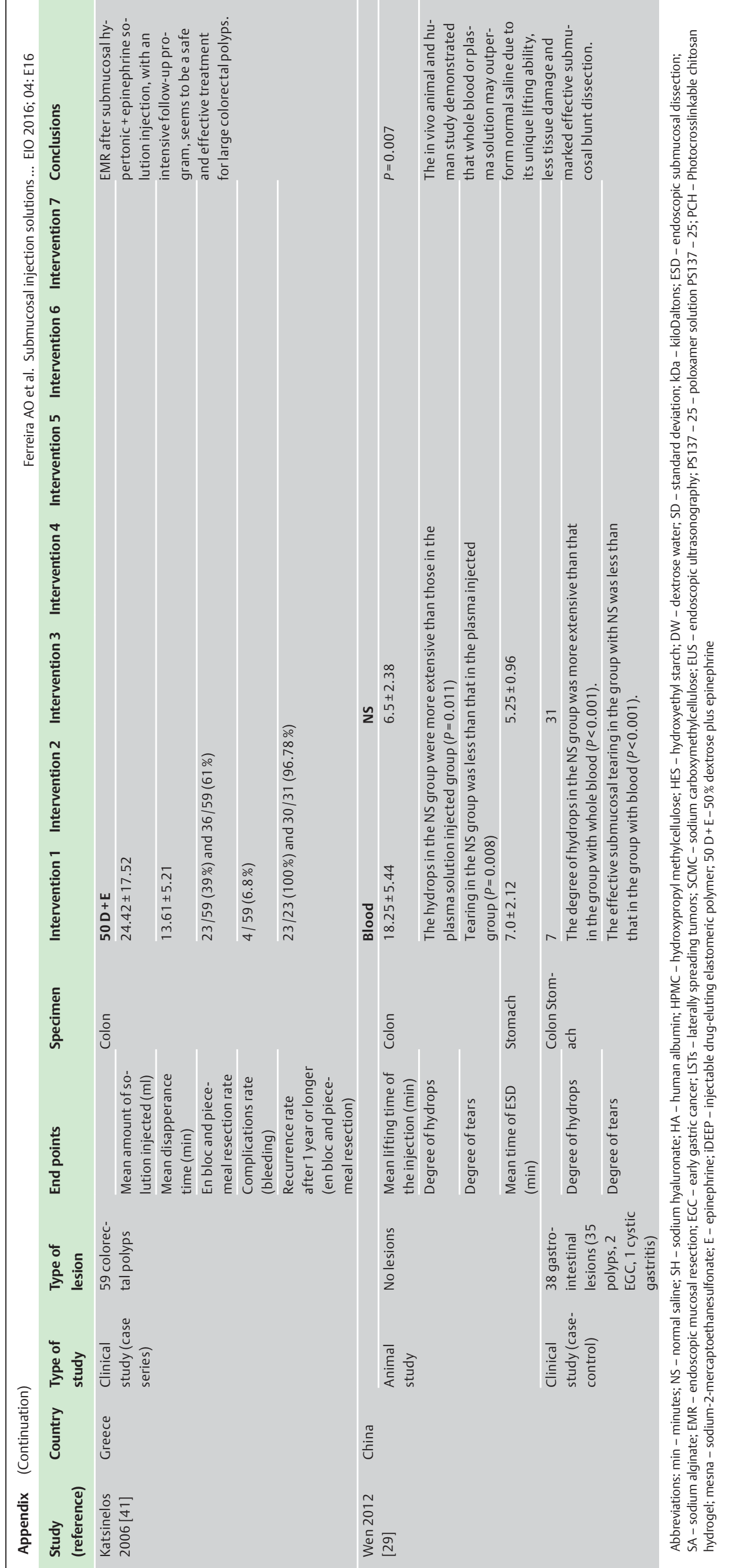

